Article

\title{
Analysis of Heat Flux Distribution during Brush Seal Rubbing Using CFD with Porous Media Approach
}

\author{
Manuel Hildebrandt, Corina Schwitzke * and Hans-Jörg Bauer
}

check for updates

Citation: Hildebrandt, M.;

Schwitzke, C.; Bauer, H.-J. Analysis of Heat Flux Distribution during Brush Seal Rubbing Using CFD with Porous Media Approach. Energies 2021, 14, 1888. https://doi.org/10.3390/ en14071888

Academic Editor: Mauro Carnevale

Received: 22 February 2021

Accepted: 25 March 2021

Published: 29 March 2021

Publisher's Note: MDPI stays neutral with regard to jurisdictional claims in published maps and institutional affiliations.

Copyright: (c) 2021 by the authors. Licensee MDPI, Basel, Switzerland. This article is an open access article distributed under the terms and conditions of the Creative Commons Attribution (CC BY) license (https:// creativecommons.org/licenses/by/ $4.0 /)$.
Institute of Thermal Turbomachinery (ITS), Karlsruhe Institute of Technology, Kaiserstraße 12, 76131 Karlsruhe, Germany; manuel.hildebrandt@kit.edu (M.H.); Hans-Joerg.Bauer@kit.edu (H.-J.B.)

* Correspondence: corina.schwitzke@kit.edu; Tel.: +49-721-608-44182

\begin{abstract}
This paper discusses the question of heat flux distribution between bristle package and rotor during a rubbing event. A three-dimensional Computational Fluid Dynamics (3D CFD) model of the brush seal test rig installed at the Institute of Thermal Turbomachinery (ITS) was created. The bristle package is modelled as a porous medium with local non-thermal equilibrium. The model is used to numerically recalculate experimentally conducted rub tests on the ITS test rig. The experimentally determined total frictional power loss serves as an input parameter to the numerical calculation. By means of statistical evaluation methods, the ma in influences on the heat flux distribution and the maximum temperature in the frictional contact are determined. The heat conductivity of the rotor material, the heat transfer coefficients at the bristles and the rubbing surface were identified as the dominant factors.
\end{abstract}

Keywords: brush seal; rubbing; heat flux distribution; porous media; CFD

\section{Introduction}

Over the years, brush seals have been well established for use in stationary turbomachines and aircraft engines. The design processes are still based, to a large extent, on the manufacturers' experience. The aim of the design process is to obtain a brush seal that is subject to minimal wear during operation, but it is still stiff enough to achieve the required pressure reduction in steady-state operation (see Ref. [1])). According to Aksit and Tichy [2], the wear of brush seals, similarly to other sliding contacts, depends on three ma in factors:

\section{Material selection:}

The choice of tribological partners determines, among other things, the coefficients of friction and wear properties. These are mainly defined by yield strength, modulus of elasticity, hardness, surface quality, and formation of oxide layers.

\section{Contact mechanics:}

The contact loads are of particular importance here. They are determined by the seal design, the operating parameters, and effects, such as blow-down, pressure stiffening, and hysteresis.

\section{Heat transfer:}

In particular, the temperature level in the friction contact has a direct effect on the mechanical and physical material properties of the sliding partners and the tribochemical reactions, such as the formation of oxide layers. The temperatures in the friction contact are determined by the level of the ambient air temperature and the heat input during the contact with the seal. These changes also indirectly affect the friction coefficient $\mu$. In addition to the knowledge of the heat input in friction contact, the distribution of heat fluxes between the bristle package and the seal and, subsequently, the distribution within the bristle package are also important. In brush 
seals, these distributions are strongly influenced by cooling effects due to leakage. In the following, only the third factor, the heat transfer, will be discussed.

Already, in 1988, Gorelov et al. [3] recognized that a reduction of the leakage rate results in a significant heating of the brush seal. Accordingly, even small amounts of air are sufficient to cool the bristles adequately. The heat transfer within the package is comparable to that of a heat exchanger (see Ref. [4]). In this respect the diameter of the bristles and the cavities between the bristles play a decisive role.

With the help of a numerical flow simulation with modelling of the bristle package as a porous medium, Doğu and Aksit [5] calculated temperature profiles in the bristle package as a function of directly specified heat inputs in the friction contact. The maximum temperatures always occur at the bristle tips and decrease exponentially in radial direction to the level of the air inlet temperature. In the axial direction, a very uniform temperature distribution was determined. However, the authors assumed an isotropic heat conduction in the package. In reality, this is strongly anisotropic due to the orientation of the bristles and the bristle spaces. The highest radial temperature drop was found in the area of the back plate. The convective cooling effect increases due to higher leakage rates at high pressure differences. This, in turn, reduces the temperature level and increases the radial temperature gradient.

Demiroglu and Tichy [6] developed a semi-empirical equation in closed form to calculate the contact forces. This was used to calculate the friction power (see Ref. [7]):

$$
P_{\text {fric }}=\mu \cdot F_{\mathrm{N}} \cdot u .
$$

In order to validate the equation, rub tests were carried out and the temperatures at the rotor and at the downstream bristles were measured by infrared thermography. Because the part of the equation used is only valid without a pressure difference applied, no flow was applied in the validation measurements. The calculated frictional power served as an input variable for a finite element analysis. Therefore, the assumption was made that the heat flux between the rotor and seal is split in a ratio of 50:50. This was justified with similar heat conduction coefficients and an identical contact surface. However, further measurements have shown that this assumption is no longer valid under pressurisation. In this case, the heat flux distribution changes very much in favour of the bristles.

On the same test rig that was used by Demiroglu and Tichy [6], Ruggiero et al. [8,9] carried out steady-state, pressureless rub tests with brush seals with non-metallic bristles of aramid and carbon fibres. By means of a subsequent FE analysis, the heat input into the rotor was determined by iteratively adjusting this value until the calculated temperature gradients matched the measured ones. Following Demiroglu's and Tichy's hypothesis that, in the absence of flow through the seal, the heat flux distribution mainly depends on the thermal conductivity of the materials, Ruggiero et al. [8] assumed that, due to the low thermal conductivity of Kevlar, almost all of the heat should flow into the rotor.

Qiu and Li [10] used a numerical flow simulation to calculate the pressure forces. They did not resolve the individual bristles, but modelled the entire package as a porous medium. The contact forces were iteratively calculated with an FE model, taking into account the friction and deflection of the bristles. The frictional power was determined according to Equation (1). A constant friction coefficient of 0.24 was used. The resulting frictional power served as input for the Computational Fluid Dynamics (CFD) simulation. For the heat transfer in the bristle package, they assumed a local thermal equilibrium, i.e. the local air temperature corresponded to the bristle temperature. In a subsequent publication, the assumption of a local thermal equilibrium was replaced by an equation considering the convective heat transfer in the bristle package (see Ref. [11]). In order to determine the heat transfer coefficients at the bristles, they used correlations for banks of staggered tubes, as done by Doğu and Aksit [5]. The calculations showed an increase in the maximum temperatures in friction contact with increasing differential pressure, but a lower mean temperature in the package. With increasing speed, the maximum 
temperature and the mean temperature in the package also increased. As the temperature increased, a reduction in leakage was found. This is explained by a decreasing density of the streaming fluid.

Pfefferle et al. presented an instrumentation concept for the measurement of rotor temperatures during rubbing [12]. They placed thermocouples below a radially thin-walled rotor at six axial positions. For redundancy, the instrumentation was mirrored at a circumferential position offset by $180^{\circ}$. The thermocouple tips were welded to the rotor and the thermocouple lines were fixed with spot-welded sheets. In order to calculate the heat input into the rotor, an FE model was created and the heat input, as a boundary condition of the simulation, was iteratively varied until the best possible agreement between the experimental and numerical temperature curves was obtained. During the tests, the resulting total frictional power was calculated by subtracting the power measured before and during the rubbing. The difference between total frictional power and rotor heat input results in the heat input into the bristles and the air. Pfefferle [13] published the results of these tests. The tests were carried out with four seals of the clamped design, which are identical in design. Over all tests, it was calculated that $60-90 \%$ of the total frictional power goes into the rotor. Pfefferle [13] tried to model the transient behaviour of the experimental rubbing tests with a duration of $30 \mathrm{~s}$ in an additional simplified FE model in order to investigate these heat flux distributions in more detail. He was able to show that the transient test procedure leads to more heat being conducted into the rotor by up to $9 \%$ than would be the case in steady-state operation. A variation of the heat transfer coefficients showed that only for $\alpha_{\mathrm{b}}<100 \mathrm{~W} /\left(\mathrm{m}^{2} \mathrm{~K}\right)$, more heat is conducted into the rotor. Pfefferle [13] explains this by an anisotropic arrangement of the bristles in axial and tangential direction, which results in little or no flow through parts of the bristle package (see also Ref. [14]). Pfefferle [13] believes that the worn bristle package itself provides a further explanation: agglomerated wear material at the bristle tips and severely deformed bristles reduce the leakage flow in the area in direct contact with the rotor. Both reasons lead to a reduction of convective heat transfer due to the reduced flow velocities. This is in contradiction to the correlations for banks of staggered tubes previously used for brush seals to calculate the heat transfer coefficients (see Refs. $[11,15,16]$ ).

The work by Pfefferle [13] was continued at the ITS in the subsequent years on a modified test rig (see Refs. [17-20]). The experimental investigations that were presented in these publications with subsequent calculation of the rotor heat input using an FE model demonstrated the influence of the geometry and operating parameters, as well as the degree of contamination of the bristle package on the heat flux distribution. When considering all of the experiments, it can be concluded that, in most cases, a large part of the frictional power generated is dissipated into the rotor.

The aim of this paper is to show the ma in factors influencing the heat flux distribution. The knowledge gained will be used to verify whether, as assumed by Pfefferle [13], the heat transfer coefficients at the bristles are significantly lower than that predicted by the correlations usually used for banks of staggered tubes. For this purpose, selected rub tests with seal 1 at different differential pressures are numerically simulated. The calculations include seal and rotor as well as the flow fields upstream and downstream of the seal. Hildebrandt previously published this numerical study (see Ref. [21]). The experimental results of the rub tests with this seal were published in [18].

Several approaches are available for modelling the flow in the bristle package. Besides the semi-empirical approaches ("bulk flow models") and models with fully dissolved bristles, calculation approaches in which the bristle package is modelled as a porous medium have been established. When modelling the real geometry, the complete flow channels between the bristles within the package have to be meshed. Because of the small wire diameters in combination with high packing densities, this means an increased modelling and calculation effort. Furthermore, it is difficult to model the axially and radially variable bristle spacing according to a real brush seal. The approach of modelling the bristle packing by means of a porous medium overcomes the problems of this dynamic 
movement and the complex structure of the bristle package. For this reason, the following calculations are based on a modelling of the bristle package while using a porous medium.

\section{Basic Equations for Calculating Flow Losses and Heat Transfer in Porous Media}

The equations that are used to calculate the leakage flow of a brush seal are described below. Outside the bristle package, the usual Navier-Stokes equations are used. To account for the flow resistance that the bristles exert on the fluid, an additional resistance force $\vec{F}_{\mathrm{r}}$ per unit volume is defined within the bristle pack:

$$
\vec{F}_{\mathrm{r}}=-\mathbf{A} \mu \vec{v}-\mathbf{B} \rho|v| \vec{v}
$$

This resistance is composed of a viscosity and an inertia term. Equation (2) is based on the results that were obtained by Darcy [22] and Forchheimer [23], and it is called the Forchheimer equation in its basic form. Because of the anisotropic composition of the bristle package, the flow losses are also directional. For example, the losses parallel to the longitudinal axis of the bristles are significantly lower than those transverse to the longitudinal axis of the bristles. However, they are largely responsible for the radial pressure gradient in the bristle package. As a result, the tensors $\mathbf{A}$ and $\mathbf{B}$ each consist of three elements:

$$
\mathbf{A}=\left[\begin{array}{ccc}
a_{\mathrm{x}} & 0 & 0 \\
0 & a_{\mathrm{s}} & 0 \\
0 & 0 & a_{\mathrm{n}}
\end{array}\right], \mathbf{B}=\left[\begin{array}{ccc}
b_{\mathrm{x}} & 0 & 0 \\
0 & b_{\mathrm{s}} & 0 \\
0 & 0 & b_{\mathrm{n}}
\end{array}\right]
$$

The coefficients are related to a local coordinate system, which is defined relative to the individual bristles. The ma in directions $e_{\mathrm{x}}, e_{\mathrm{s}}$, and $e_{\mathrm{n}}$ are defined, as follows:

- $\quad e_{\mathrm{x}}$ : parallel to the $x$-axis of the test rig,

- $e_{\mathrm{s}}$ : parallel to the bristle longitudinal axis, and

- $\quad e_{\mathrm{n}}$ : perpendicular to $x$-axis and bristle longitudinal axis.

For the determination of the coefficients $a_{\mathrm{i}}$ and $b_{\mathrm{i}}$, the findings from Ergun [24] can be applied, who investigated the flow through porous media in a Reynolds number range relevant to brush seals. According to Ergun [24], Equation (2) can be represented for the isotropic case as pressure loss over the height of the layer bed in the following way:

$$
\frac{\Delta p}{L}=\frac{\tilde{\alpha} \cdot \mu \cdot(1-\epsilon)^{2}}{\tilde{d}^{2} \cdot \epsilon^{3}} \cdot V+\frac{\tilde{\beta} \cdot \rho \cdot(1-\epsilon)}{\tilde{d} \cdot \epsilon^{3}} \cdot V^{2} .
$$

The coefficients $a_{\mathrm{i}}$ and $b_{\mathrm{i}}$ are, thus, proportional to $(1-\epsilon)^{2} / \epsilon^{3}$ and $(1-\epsilon) / \epsilon^{3}$, respectively. The variable $\epsilon$ represents the porosity of the medium through which the medium flows. It is defined as the ratio of the void volume to its total volume:

$$
\epsilon=\frac{V_{\mathrm{f}}}{V_{\mathrm{tot}}}=1-\frac{V_{\mathrm{s}}}{V_{\mathrm{tot}}} .
$$

The porosity used for brush seals is described, in detail, in Section 2.2.

The diameter $\tilde{d}$ shown in Equation (4) represents the equivalent sphere diameter:

$$
\begin{gathered}
\tilde{d}=\frac{6}{a_{\mathrm{v}}}, \\
a_{\mathrm{v}}=\frac{A}{V}=\frac{d_{\mathrm{b}} \cdot \pi \cdot l}{1 / 4 \cdot d_{\mathrm{b}}^{2} \cdot \pi \cdot l}=\frac{4}{d_{\mathrm{b}}} .
\end{gathered}
$$

On the basis of measurements with packed beds of spherical particles, Ergun [24] suggests the factors $\tilde{\alpha}=150$ and $\tilde{\beta}=1.75$. With respect to the wire diameter $d_{\mathrm{b}}$ of the brush seal, Equation (6) gives the factors $\alpha=\tilde{\alpha} / \tilde{d}^{2} \cdot d_{\mathrm{b}}^{2}=66.7$ and $\beta=\tilde{\beta} / \tilde{d}^{2} \cdot d_{\mathrm{b}}^{2}=1.17$. In order to obtain a better match with the application under consideration of the brush seal, which resembles 
a cylinder packing, Chew and Hogg [25] and Proestler [26] suggest the factors $\alpha=80$ and $\beta=1.16$.

The coefficients $a_{\mathrm{x}}$ and $a_{\mathrm{n}}$ or $b_{\mathrm{x}}$ and $b_{\mathrm{n}}$ can be represented according to Equation (4), as follows:

$$
\begin{aligned}
& a_{\mathrm{x}}=a_{\mathrm{n}}=\frac{\alpha \cdot(1-\epsilon)^{2}}{d_{\mathrm{b}}^{2} \cdot \epsilon^{3}}=\frac{80 \cdot(1-\epsilon)^{2}}{d_{\mathrm{b}}^{2} \cdot \epsilon^{3}}, \\
& b_{\mathrm{x}}=b_{\mathrm{n}}=\frac{\beta \cdot(1-\epsilon)}{d_{\mathrm{b}} \cdot \epsilon^{3}}=\frac{1,16 \cdot(1-\epsilon)}{d_{\mathrm{b}} \cdot \epsilon^{3}} .
\end{aligned}
$$

Chew et al. gave the loss coefficient $a_{\mathrm{S}}$ along the bristle axis [27], based on a comparison of experimental and numerical results, with a ratio of 1:60 to the losses transverse to the bristle axis. In contrast, Proestler [26] calculated an analytical expression assuming the pressure reduction of a laminar flow in non-circular pipe sections. Proestler [26] calculated the factor $a_{\mathrm{s}}$, as:

$$
a_{\mathrm{s}}=\frac{32 \cdot \epsilon \cdot(1-\epsilon)^{2}}{d_{\mathrm{b}}^{2} \cdot \epsilon^{3}}=\frac{32 \cdot(1-\epsilon)^{2}}{d_{\mathrm{b}}^{2} \cdot \epsilon^{2}} .
$$

The dissipative losses along the bristle axis are neglected and the factor $b_{\mathrm{s}}$ is set to zero. The numerical calculations performed in this paper use the loss coefficients according to Proestler [26] .

\subsection{Energy Conservation Equations}

In general, two cases can be distinguished for heat transfer in porous media: The simple case of thermal equilibrium between the solid and the fluid and the case where there is a significant temperature difference between the two. In the case of a typical flow through the bristle package of a brush seal, strong forced convection occurs between the bristles and the leakage air, so that the second case applies. This is modelled using a double cell approach. Such an approach defines a fixed zone that spatially coincides with the porous fluid zone. This solid zone only interacts with the fluid in terms of heat transfer. The conservation equations for energy are separately solved for the fluid and solid zones. The conservation equation solved for the fluid zone is in accordance with Nield and Bejan [28]:

$$
(1-\epsilon)(\rho c)_{\mathrm{s}} \frac{\partial T_{\mathrm{s}}}{\partial t}=(1-\epsilon) \nabla \cdot\left(\lambda_{\mathrm{s}} \nabla T_{\mathrm{s}}\right)+\alpha_{\mathrm{fs}} a_{\mathrm{fs}}\left(T_{\mathrm{f}}-T_{\mathrm{s}}\right)
$$

and for the solid zone

$$
\epsilon\left(\rho c_{\mathrm{p}}\right)_{\mathrm{f}} \frac{\partial T_{\mathrm{f}}}{\partial t}+\left(\rho c_{\mathrm{p}}\right) \vec{v} \cdot \nabla T_{\mathrm{f}}=\epsilon \nabla \cdot\left(\lambda_{\mathrm{f}} \nabla T_{\mathrm{f}}\right)+\alpha_{\mathrm{fs}} a_{\mathrm{fs}}\left(T_{\mathrm{s}}-T_{\mathrm{f}}\right) .
$$

$\alpha_{\mathrm{fs}}$ is the heat transfer coefficient between the fluid and the solid and $a_{\mathrm{fs}}$ is the specific surface area of the solid. Relating to the wire package of a brush seal, $a_{\mathrm{fs}}$ equals to:

$$
a_{\mathrm{fs}}=(1-\epsilon) \frac{d_{\mathrm{b}} \cdot \pi \cdot l}{1 / 4 \cdot d_{\mathrm{b}}^{2} \cdot \pi \cdot l}=(1-\epsilon) \frac{4}{d_{\mathrm{b}}}=(1-\epsilon) \cdot a_{\mathrm{v}} .
$$

With regard to the heat conduction within the bristle package, it should be noted that, similar to the loss coefficients, it is also directional. Perpendicular to the longitudinal axis of the bristle, an effective heat conduction $\lambda_{\text {eff }}$ can be calculated, which results from a series connection of the heat conduction of the solid and fluid (see Ref. [29]):

$$
\begin{gathered}
\frac{1}{\lambda_{\text {eff }}}=\frac{\epsilon}{\lambda_{\mathrm{f}}}+\frac{(1-\epsilon)}{\lambda_{\mathrm{s}}}, \\
\lambda_{\text {eff }}=\lambda_{\mathrm{s}, \mathrm{x}}=\lambda_{\mathrm{s}, \mathrm{n}}=\lambda_{\mathrm{f}, \mathrm{x}}=\lambda_{\mathrm{f}, \mathrm{n}}=\frac{\lambda_{\mathrm{f}} \cdot \lambda_{\mathrm{s}}}{(1-\epsilon) \cdot \lambda_{\mathrm{f}}+\epsilon \cdot \lambda_{\mathrm{s}}} .
\end{gathered}
$$


Equations (11) and (12), in combination with Equation (15), lead to:

$$
\begin{array}{r}
(1-\epsilon)(\rho c)_{\mathrm{s}} \frac{\partial T_{\mathrm{s}}}{\partial t}=(1-\epsilon)\left[\frac{\partial}{\partial x}\left(k_{\mathrm{eff}} \frac{\partial T_{\mathrm{s}}}{\partial x}\right)+\frac{\partial}{\partial s}\left(k_{\mathrm{s}} \frac{\partial T_{\mathrm{s}}}{\partial s}\right)\right. \\
\left.+\frac{\partial}{\partial n}\left(k_{\mathrm{eff}} \frac{\partial T_{\mathrm{s}}}{\partial n}\right)\right]+\alpha_{\mathrm{fs}} a_{\mathrm{fs}}\left(T_{\mathrm{f}}-T_{\mathrm{s}}\right), \\
\epsilon\left(\rho c_{\mathrm{p}}\right)_{\mathrm{f}} \frac{\partial T_{\mathrm{f}}}{\partial t}+\left(\rho c_{\mathrm{p}}\right) \vec{v} \cdot \nabla T_{\mathrm{f}}=\epsilon\left[\frac{\partial}{\partial x}\left(k_{\mathrm{eff}} \frac{\partial T_{\mathrm{f}}}{\partial x}\right)+\frac{\partial}{\partial s}\left(k_{\mathrm{f}} \frac{\partial T_{\mathrm{f}}}{\partial s}\right)\right. \\
\left.+\frac{\partial}{\partial n}\left(k_{\mathrm{eff}} \frac{\partial T_{\mathrm{f}}}{\partial n}\right)\right]+\alpha_{\mathrm{fs}} a_{\mathrm{fs}}\left(T_{\mathrm{s}}-T_{\mathrm{f}}\right) .
\end{array}
$$

\subsection{Porosity of the Brush Seal}

Referring to a cylinder packing, as in the case of a brush seal, the porosity can be expressed, as follows:

$$
\epsilon=1-\frac{\pi \cdot d_{\mathrm{b}}^{2} \cdot \rho_{\mathrm{p}}}{4 \cdot B \cdot \sin (\lambda)} .
$$

In Equation (18), it was neglected that the porosity is dependent on the radius. Because the circumferential area increases with increasing radius, but the number of bristles remains constant, the porosity increases in the outward radial direction. According to Qiu et al. [11], the porosity as a function of the radius can be calculated, as follows:

$$
\begin{array}{r}
\epsilon(r)=1-\frac{\rho_{\mathrm{p}} \pi D_{\mathrm{R}}(\Delta r / \sin (\lambda))\left(\pi d_{\mathrm{b}}^{2} / 4\right)}{\left(\pi(r+\Delta r)^{2}-\pi r^{2}\right) B} \\
=1-\frac{\rho_{\mathrm{p}} \pi D_{\mathrm{R}} d_{\mathrm{b}}^{2} / \sin (\lambda)}{4 B(\Delta r+2 r)} .
\end{array}
$$

For $\Delta r \rightarrow 0$ follows from Equation (19):

$$
\epsilon(r)=1-\frac{\rho_{\mathrm{p}} \cdot \pi \cdot D_{\mathrm{R}} \cdot d_{\mathrm{b}}^{2}}{8 \cdot B \cdot r \cdot \sin (\lambda)} .
$$

In addition to the fixed geometric parameters, such as the wire diameter $d_{\mathrm{b}}$, the rotor outer diameter in relation to the package centre $D_{R}$, and the laying angle $\lambda$, the porosity also depends on a size that changes depending on the operating pressure applied, namely the package width $B$ (see Refs. [30,31]). Consequently, this size must be taken into special consideration when calibrating the model (see Section 4). Here, it is neglected that the laying angle $\lambda$ also changes during rubbing, due to the radial deflection of the bristles. However, the changes are very small.

\section{Description of the Model}

In Figure 1, the computational doma in of the numerical calculations is shown. It consists of a $0.5^{\circ}$ section of the ITS brush seal test rig (see Ref. [18]).

Periodic boundary conditions are set in circumferential direction because of the rotational symmetry. The calculation doma in includes the rotor, the test seal, the axial brush seal, a part of the seal holder, and the flow areas upstream and downstream of the test seal. The test seal is modelled as a porous medium, assuming that there is no thermal equilibrium between the bristles and the fluid. The axial brush seal is also modelled as a porous medium, assuming that there is a thermal equilibrium. The calculation doma in starts at a radius of $50 \mathrm{~mm}$. The recalculation of the experimental tests by means of the FE analyses (see Refs. [17-19]) has shown that the areas further inwards are only slightly thermally affected within the rubbing period of $30 \mathrm{~s}$. 


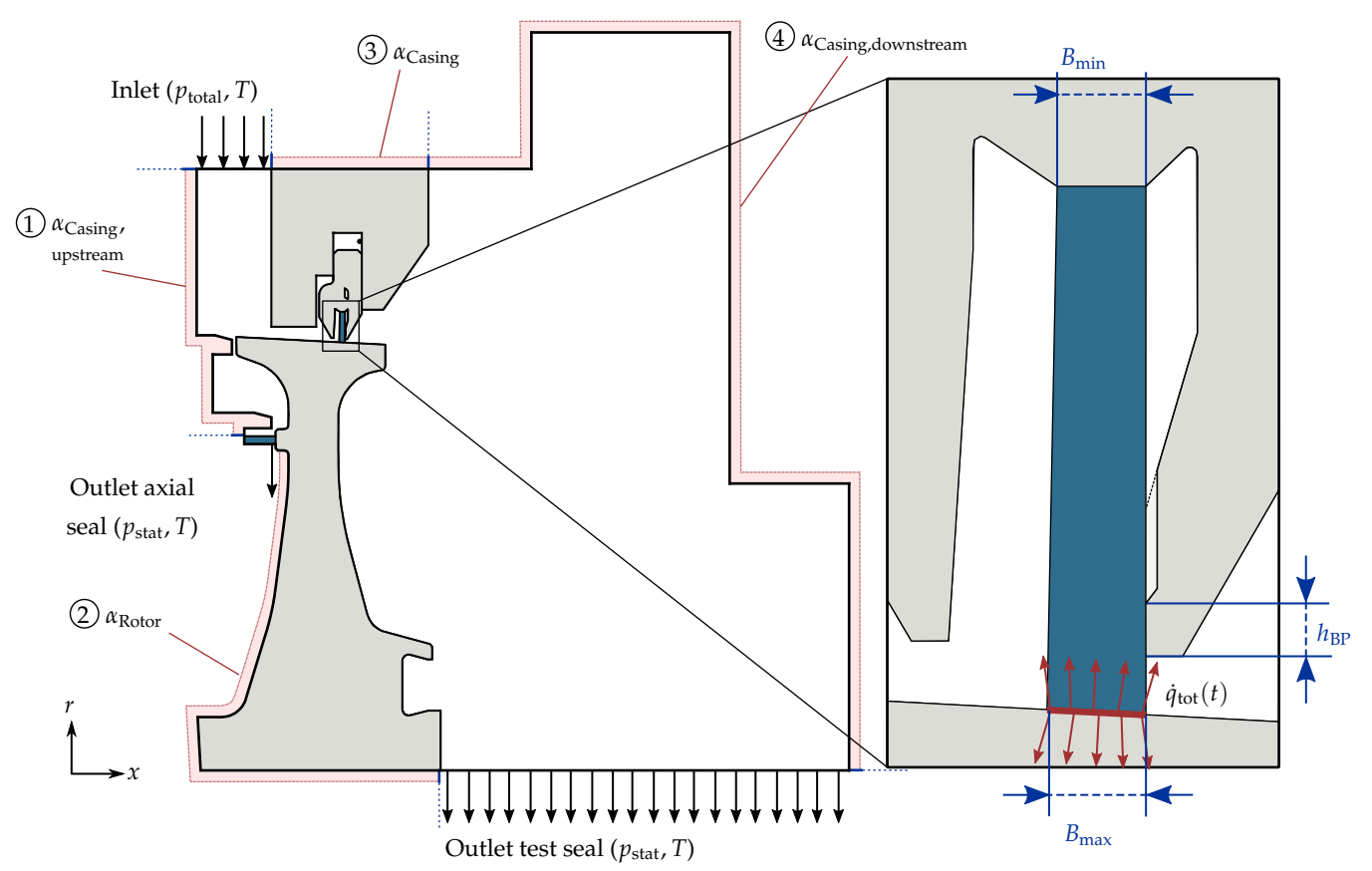

Figure 1. Computational doma in of the numerical model; Fluid ( $\square$ ), Solid ( $\square$ ), Porous media ( $\square$ ).

At the inlet, the total pressure and temperature are set according to the respective measured values from the experiments. At the outlets, the static pressures and temperatures are specified. At the outer surfaces (1)-(4), appropriate heat transfer boundary conditions are defined. Along the outer contour of the rotor, a circumferential speed corresponding to the tests is set. In the detailed section in Figure 1, it can be seen that the specific total frictional power loss $\dot{q}_{\text {tot }}$ is applied to the contact area between the seal and rotor:

$$
\dot{q}_{\text {tot }}(t)=\frac{P_{\text {tot }}(t)}{A} \cdot(1-\epsilon) .
$$

This quantity is based on the measurement of the total power loss during the experiments. Similar to the temperatures at the inlets and outlets, it is defined as time-dependent and specified as a boundary condition. The heat flux distribution will be self-adjusting due to the prevailing conditions. In the detailed section, it is also evident that the package width is not constant over the height. In the clamping area, the package width is defined to the minimum package width (see Section 4). The package width increases towards the inside and it reaches its maximum value at the contact point to the rotor. This specification is based on own observations and descriptions by other authors (e.g. Ref. [30]). A narrow gap was defined between the bristle package and the back plate, thus reducing the contact height of the bristles on the back plate $h_{\mathrm{BP}}$. In various publications (e.g. Refs. [32-34]), it has been described how the bristle package bends in axial downstream direction below the back plate when a pressure difference is applied. As a result, there is a bending in the upper area in the upstream direction and, thus, a reduction of the contact surface. This effect is to be replicated by reducing the contact surface in the model. The contact height at the back plate has an influence on the radial pressure drop and, thus, on the pressures in the pressure relief chamber, as well as on the heat transfer.

The axial position of the seal relative to the rotor is adjusted individually for all test cases, analogously to the experiment. In addition, the determined rotor elongation is taken into account to adjust the gap below the back plate as closely as possible to the gap during the rub tests.

\subsection{Investigated Test Cases}

The numerical test cases that are examined are based on rub tests of seal 1 under variation of the differential pressure (see Ref. [18]). The bristle package consists of bristles 
of Haynes 25 with a bristle diameter $d_{\mathrm{B}}$ of $0.07 \mathrm{~mm}$, a package density $\rho_{\mathrm{p}}$ of $200 \mathrm{Bpmm}$ and a seal inner diameter of $300 \mathrm{~mm}$. The laying angle of the bristles $\lambda$ is $45^{\circ}$. The rotor is made of Inconel 718 and it has a diameter of $299.5 \mathrm{~mm}$ on the right front edge. The cone angle of the rubbing surface is $2.95^{\circ}$. The pressure difference was varied in the steps of 1.0, 2.5, 4.0, 5.5 and 7.0 bar. The choice was made for these test points, because the largest influences on the heat flux distribution have been observed in the experiment when varying the pressure difference and the heat transfer coefficients at the bristles $\alpha_{\mathrm{fs}}=\alpha_{\mathrm{b}}$ must change over a wide range.

The heat transfer coefficients $\alpha_{\mathrm{b}}$ are determined according to correlations for banks of staggered tubes by Gnielinski [35], Žukauskas [36], and Mart in [37]. Appendix A describes the calculation of the coefficients. Figure 2 shows the calculated values. The mean values were used for the numerical simulations. The error bars, which span an interval of $\pm 50 \%$, show that the correlations yield very different results. The heat transfer coefficients were assumed to be constant in the entire bristle package.

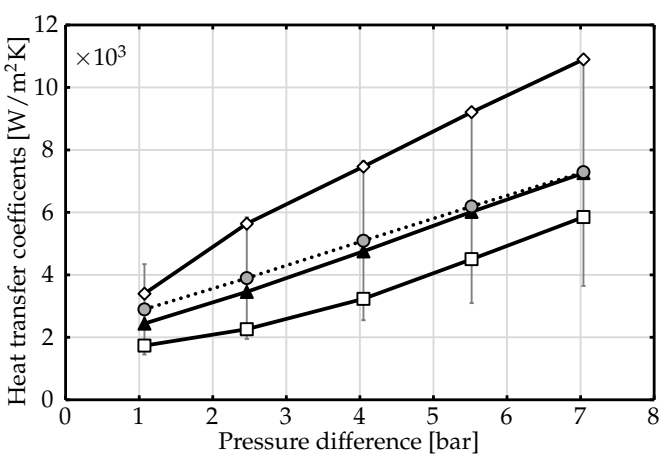

Figure 2. Heat transfer coefficients at the bristles $\alpha_{\mathrm{b}}$; Gnielinski [35] ( $\left.\diamond\right)$, Žukauskas [36] (

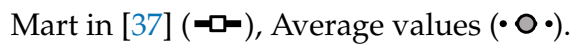

Besides the heat transfer coefficients at the bristles, the porosity $\epsilon$ is a very important parameter of the modelling. The porosity was calculated according to Equation (20), i.e., the radial dependence of the porosity was taken into account. Furthermore, it was taken into account that the bristle package tapers with increasing radial height. In Figure $3 a, b$, it can be seen that the consideration of these effects has a very large influence on the porosity.

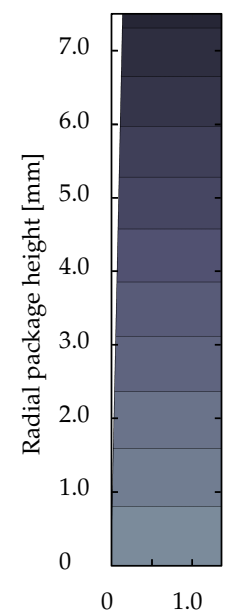

(a)

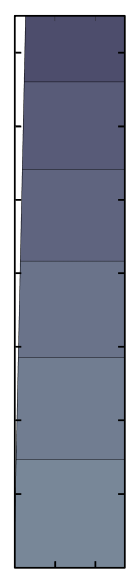

Package wid

(b)

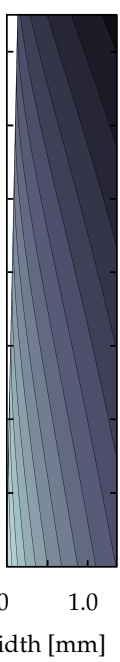

(c)

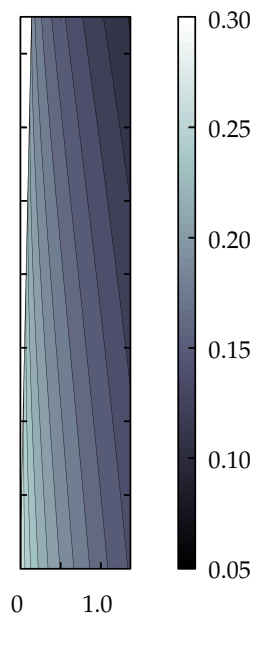

(d)

Figure 3. Distribution of porosity $\epsilon$ in the bristle package with consideration of: (a): width, (b): radius, $(\mathbf{c})$ : width + ax. compression, and $(\mathbf{d})$ : width + radius + ax. compression

The first figure shows the values of porosity under sole consideration of the variable package width. Because of the package width $B_{\min }$ defined as the minimum possible 
width in the area of the clamping, the porosity decreases strongly towards the inside. If it is also taken into account that the available space increases with increasing package height, the decrease in porosity is much less pronounced (see Figure $3 b$ ). To further take into account that the bristle package in the area of the back plate is compressed more than the bristles upstream when a pressure difference is applied, the porosity was modified according to Equation (22):

$$
\epsilon(r, x)=\epsilon \cdot\left(1+\frac{B^{(n-m)}}{n+1}\right)-\epsilon \frac{x^{n}}{B^{m}}, \quad \text { with } n=0,5 ; m=0,45 .
$$

Figure $3 \mathrm{c}$ shows the porosity when considering the package width and the weighting according to Equation (22). In the last contour plot, all of the effects are finally combined (see Figure 3d).

\subsection{Mesh Independence Study}

A mesh independence study was carried out in order to assess the influence of the created mesh on the quality of results. The analysis was performed for the medium pressure difference level of 4.0 bar. The mass flow, the heat flux distribution, and the maximum temperature in the friction contact serve as comparative values.

A total of four meshes with different resolutions were compared. The $k-\omega$-SST model was used to model the turbulence. Within the bristle package, laminar calculations were performed. This assumption is valid due to the low Reynolds numbers (see Refs. [38-40]). This is also confirmed in this study. Within the package, the Reynolds numbers based on bristle diameter were well below 1000. They only reach this order of magnitude in the region near the back plate gap where the highest velocities are present. At first, a steady-state solution was calculated without the imposition of a heat flux boundary condition. The fluid properties were assumed to be compressible. Subsequently, a transient calculation is performed for $30 \mathrm{~s}$ with time-dependent specification of the total frictional power loss and temperatures from the experiment. In Table 1, the results are summarized in relation to the mesh with the highest cell number:

Table 1. The results of mesh independence study

\begin{tabular}{cccc}
\hline \# Cells & Mass Flow Rate & HFD & Max. Temperature at Rubbing Contact \\
\hline 890,000 & $-4.43 \%$ & $-1.96 \%$ & $+5.7 \mathrm{~K}$ \\
$1,760,000$ & $-3.18 \%$ & $-0.84 \%$ & $+4.9 \mathrm{~K}$ \\
$3,600,000$ & $-0.94 \%$ & $+1.26 \%$ & $-0.4 \mathrm{~K}$ \\
$7,960,000$ & - & - & - \\
\hline
\end{tabular}

For the following simulations, the computational mesh with 3.6 million cells was used.

\section{Calibration of the Numerical Model}

The adaptation or calibration to the experimental data is inherent in the modelling of the bristle package by means of a porous medium. Because the geometry of the bristle package changes during operation as a function of the differential pressure, the leakage characteristics must first be calibrated. Once the numerical model has been calibrated, it can be validated using further measurement data (see Section 5). In the present study, the leakage mass flow and pressures in the pressure relief chamber must be adjusted. For the calibration of the leakage mass flow, the porosity of the bristle pack $\epsilon$ is the decisive parameter. A variation of the porosity is achieved by adjusting the package width $B$. Because the package width in the clamping area was set to the minimum value $B_{\min }$, the calibration is done by varying the package width $B_{\max }$ (see Figure 1). The minimum package width $B_{\min }$ is calculated from: 


$$
B_{\min }=d+\frac{\sqrt{3}}{2} \cdot d_{\mathrm{b}}\left(\frac{\rho_{\mathrm{p}} \cdot d_{\mathrm{b}}}{\sin (\lambda)}-1\right) .
$$

Because the bristle package is compressed depending on the pressure difference applied, the porosity also changes in the same way. Therefore, calibration must be carried out separately for each pressure stage. Figure $4 \mathrm{a}$ shows the results of the calibration of the leakage mass flows as discharge coefficients. The comparison of the numerically calculated values with the values from the experiments shows a very good agreement and, thus, a good adaptation to the experiments. Only at a pressure difference of $2.5 \mathrm{bar}$, the calculated flow rate is below the experimental value. The experimental value is most likely an outlier. A comparison of the two experimental measurement runs carried out confirms this suspicion. Because the actual course of the leakage mass flow for this pressure is not known and a linear course between the values at differential pressures of 1.0 and 4.0 bar is not necessarily present, the average package width from the package widths at differential pressures of 1.0 and 4.0 bar bar was used. In Figure $4 \mathrm{~b}$, the respective underlying package widths $B_{\max }$ are plotted over the pressure difference. It becomes apparent that, above a pressure difference of about 5.0 bar, the package is not compressed any further and the maximum sealing effect is achieved. Furthermore, it is clear that, even at the highest pressure differences, the package width is still significantly larger than the theoretical minimum package width $B_{\text {min }}$.

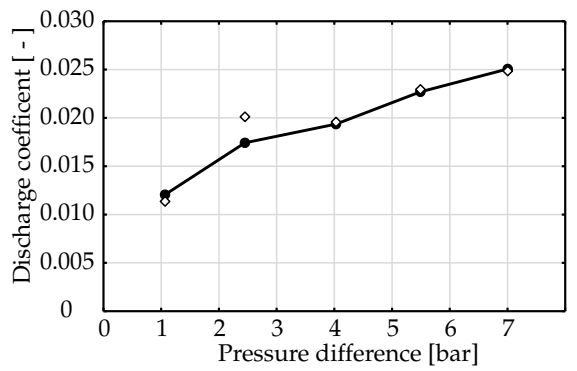

(a)

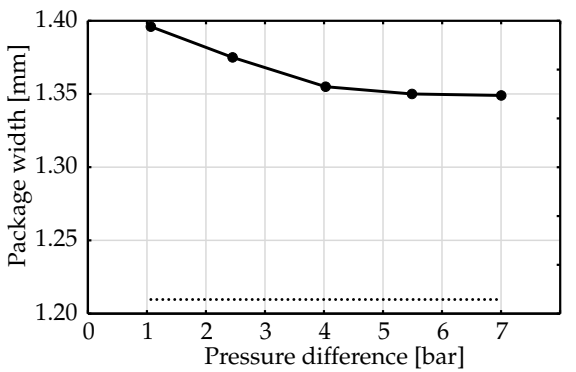

(b)

Figure 4. (a): Discharge coefficients from experiment $(\diamond)$ and numerical simulation (CFD) under variation of the pressure difference; $(\mathbf{b})$ : Package width depending on the pressure difference $(-\infty), B_{\min }(\cdots)$.

When adjusting the pressures in the pressure relief chamber, the contact height of the package at the back plate $h_{\mathrm{BP}}$ plays a decisive role in addition to the porosity of the package or the package width. The contact height has a significant influence on the radial pressure drop and, thus, the chamber pressures. In Figure 5a, the calculated and measured chamber pressures are plotted over the absolute pressure upstream of the seal. After adjusting the contact heights according to Figure $5 b$, the chamber pressures are within the measuring range. This is spanned by the deviations of the measured values at the circumferential positions of 0 and $180^{\circ}$. The decrease in the contact height with an increase in the differential pressure could, be explained by an increase in the axial deflection of the bristles and, therefore, also appears to be physically plausible, as described in Section 3. 


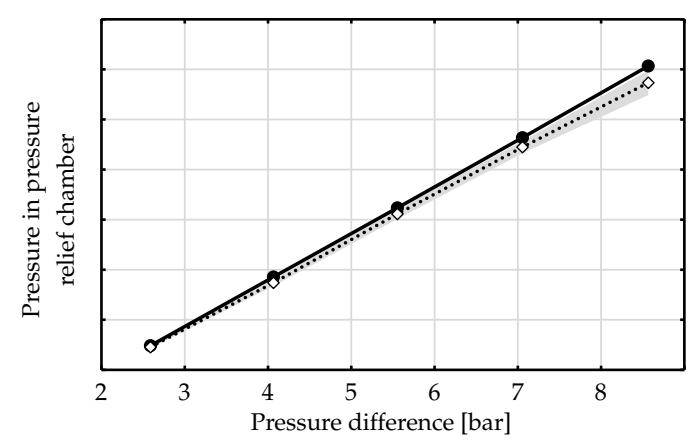

(a)

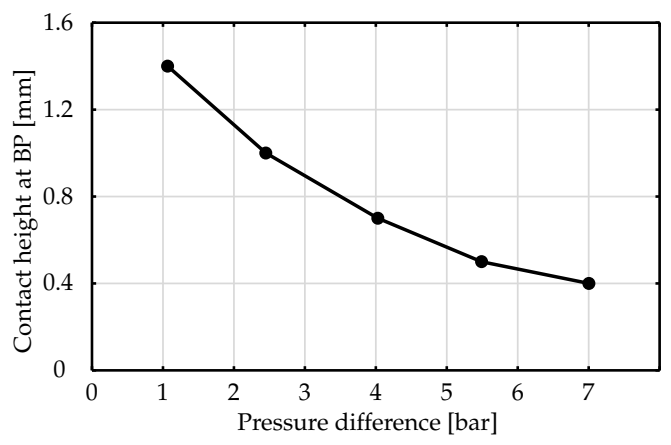

(b)

Figure 5. (a): Pressures in the pressure relief chamber as a function of the inlet pressure, experiment $(\bullet \diamond \bullet), \mathrm{CFD}(-\mathbf{-}) ;(\mathbf{b})$ : Contact height at the back plate $h_{\mathrm{BP}}$ depending on the pressure difference.

\section{Validation of the Numerical Model}

In this section, the model will be validated. Several comparison variables are available in order to be able to check whether the model reflects reality accurately. One of these variables is the pressure distribution in axial direction. In the absence of own measurement data, the results by Schur et al. [31] and Bayley and Long [41] are used. In particular, the results shown by Schur et al. [31] are suitable for a comparison, since one of the tested bristle packages corresponds exactly to that of the seal 1. In Figure 6a-e, the normalized pressures below the bristle packs are plotted over the normalized package width.

In general, the measured values of Schur et al. [31] are well matched. The pressure gradient increases in the area of the back plate, whereby this effect increases with increasing pressure difference. In Figure 6f, this can be clearly seen when looking at the numerically calculated pressure profiles. The differences between the measured values and the calculations can be explained by different operating conditions. In the experiments conducted by Schur et al. [31], a circumferential speed of $47 \mathrm{~m} / \mathrm{s}$ was present, while the measurements by Bayley and Long [41] were carried out purely statically. In the simulation, a circumferential speed almost twice as high as the value referred to by Schur et al. [31] is set. However, Schur et al. [31] could show that, with increasing speed, the pressure level also continues to rise. Furthermore, the measured values of the investigations by Schur et al. [31] are only available up to a pressure difference of 5.0 bar.

Altogether, the flow and pressure conditions can be simulated very well with the numerical model according to the experimental tests. The assumption of a rigid bristle package or the omission of the calculation of the bristle bending does not represent a significant impairment.

The measured temperatures within the rotor structure are used for validation because the flow variables are of less interest than the distribution of heat input in the rotor and seal. In addition, a comparison of the heat flux distributions are useful. The heat flux distribution is defined as the ratio of rotor heat input and the measured total frictional power loss:

$$
\text { heat flux distribution }=\frac{\text { rotor heat input }}{\text { total frictional power loss }} .
$$

The values of the heat flow distributions of the current numerical simulation are compared with those of the corresponding experimental tests (see Ref. [18]). For the experiments, the total frictional powers were measured and the rotor heat inputs were calculated by means of FE analyses. 


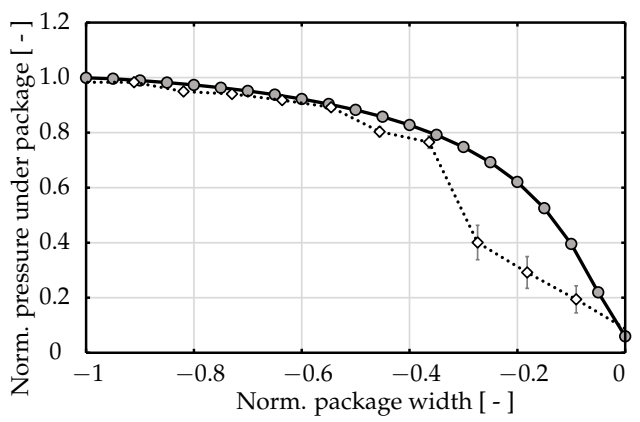

(a)

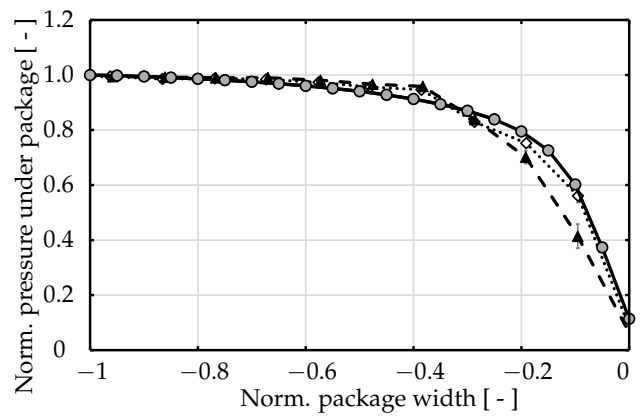

(c)

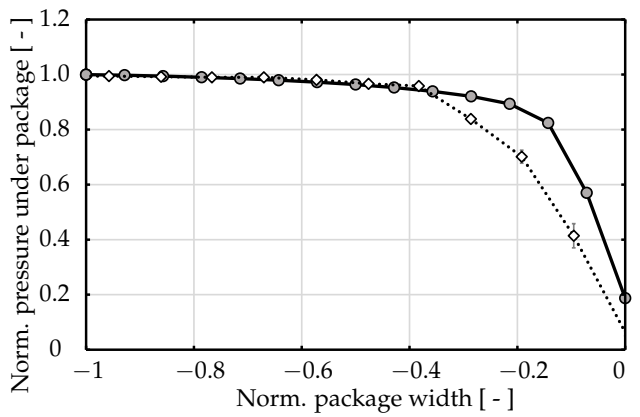

(e)

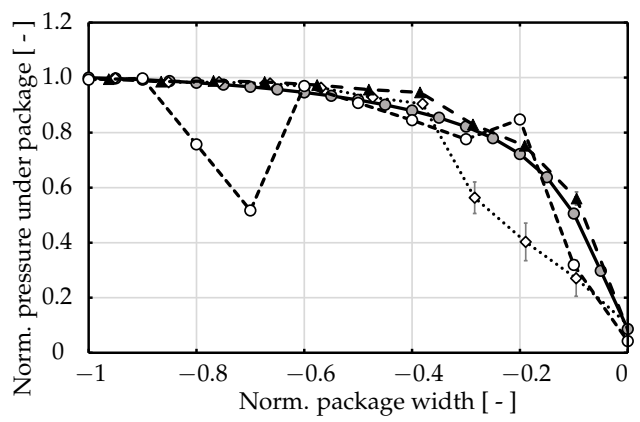

(b)

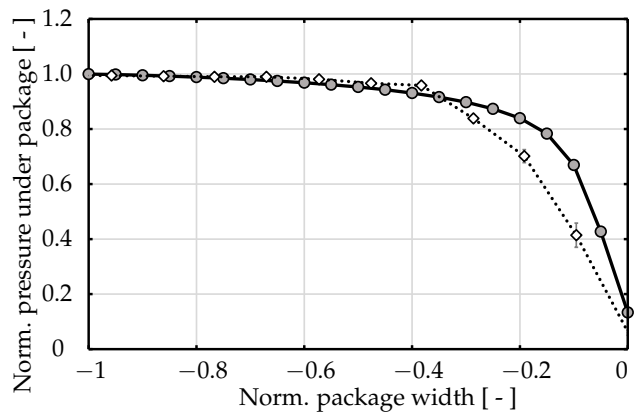

(d)

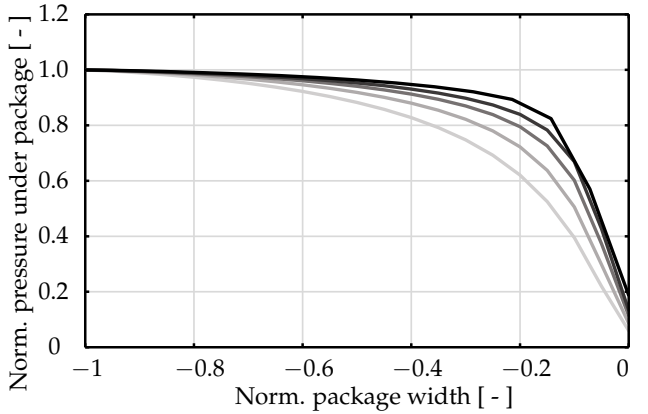

(f)

Figure 6. Norm. pressure under the package plotted against the norm. package width, (a): CFD (- - ), Schur et al. [31] $(\bullet \diamond \bullet)$, both $\Delta \mathrm{p}=1.0$ bar; (b): CFD $\Delta \mathrm{p}=2.5 \operatorname{bar}(-\mathbf{-})$, Schur (2018) $\Delta \mathrm{p}=2.0$ bar $(\bullet \diamond \bullet)$, Schur et al. [31] $\Delta \mathrm{p}=3.0$ bar (-4)), Bayley and Long [41] $R_{\mathrm{p}}<3.8$ bar (-0-); (c): CFD $\Delta \mathrm{p}=4.0$ bar

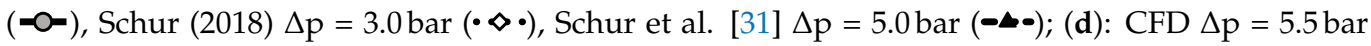
$(-\infty)$, Schur et al. [31] $\Delta \mathrm{p}=5.0$ bar $(\bullet \diamond \bullet) ;($ e): CFD $\Delta \mathrm{p}=7.0$ bar $(-\infty)$, Schur et al. [31] $\Delta \mathrm{p}=5.0$ bar $(\bullet \diamond \bullet) ;(\mathbf{f})$ : CFD $\Delta \mathrm{p}=1.0 \operatorname{bar}(-)-\Delta \mathrm{p}=7.0 \operatorname{bar}(-)$.

In Figure 7a-e, the experimental rotor temperatures are plotted together with the rotor temperatures that are determined from the numerical simulations for all five test cases. In addition, the temperature curves of the FE analysis are shown. In each case, the points in time within the contact duration of $30 \mathrm{~s}$ are shown, where the highest temperatures occurred.

While the temperature differences between the experiment and the FE analysis are very small as a matter of principle, there are stronger deviations between the experiment and numerical simulation, especially at low pressure differences. At higher pressure differences above 5.5 bar, the profiles aga in agree very well. In order to check at this point whether the hypothesis by Pfefferle [13], namely the overestimation of the heat transfer coefficients at the bristles by the correlations for banks of staggered tubes, is correct, calculations with heat transfer coefficients of $\alpha_{\mathrm{b}}=100 \mathrm{~W} /\left(\mathrm{m}^{2} \mathrm{~K}\right)$ and $\alpha_{\mathrm{b}}=1000 \mathrm{~W} /\left(\mathrm{m}^{2} \mathrm{~K}\right)$ have been performed for the first two pressure levels. The experimental temperature level is reached in the case of a heat transfer coefficient of $\alpha_{b}=100 \mathrm{~W} /\left(\mathrm{m}^{2} \mathrm{~K}\right)$ and a pressure difference of 2.5 bar. The calculated temperatures are too low for all other cases. 


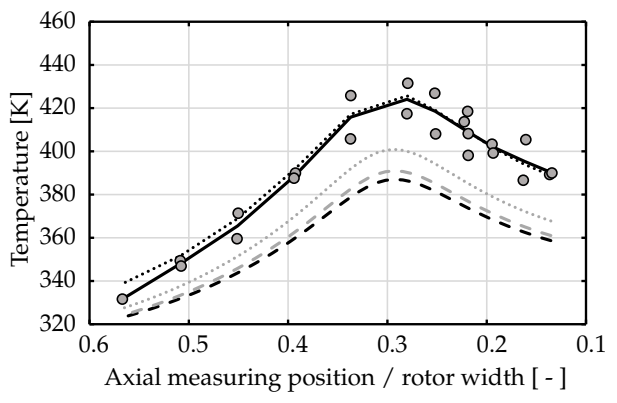

(a)

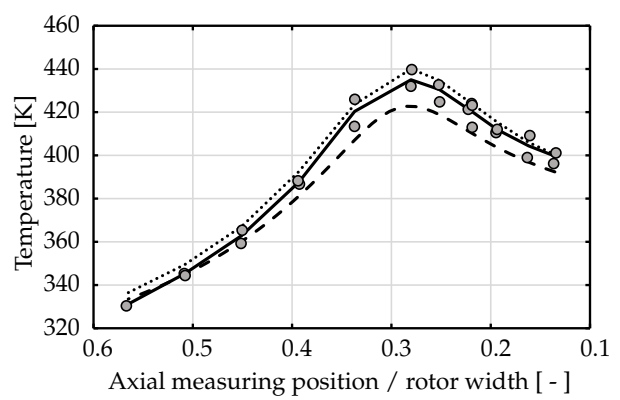

(c)

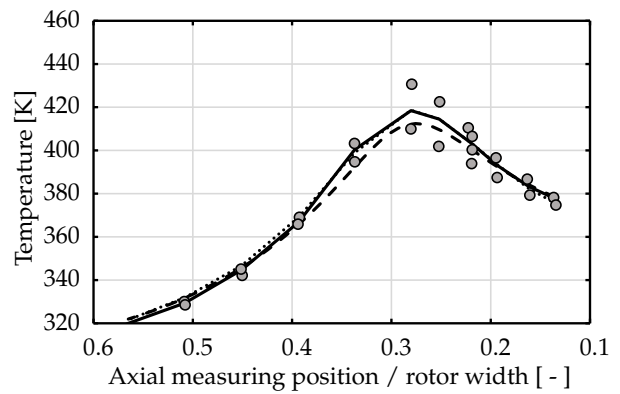

(e)

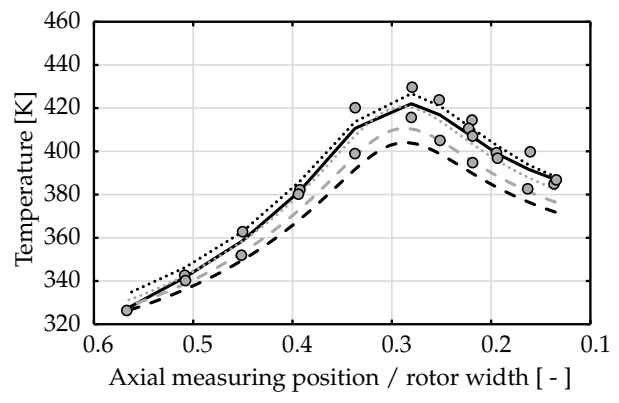

(b)

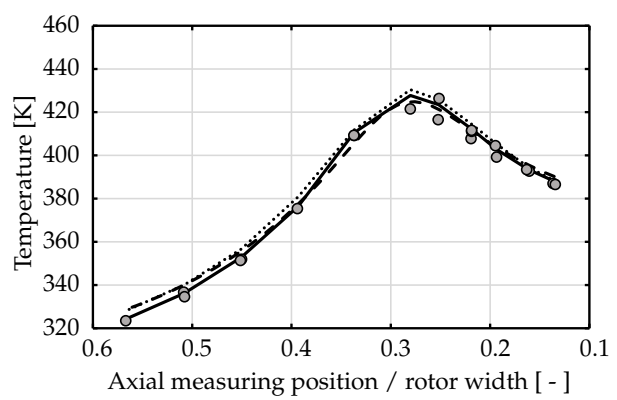

(d)

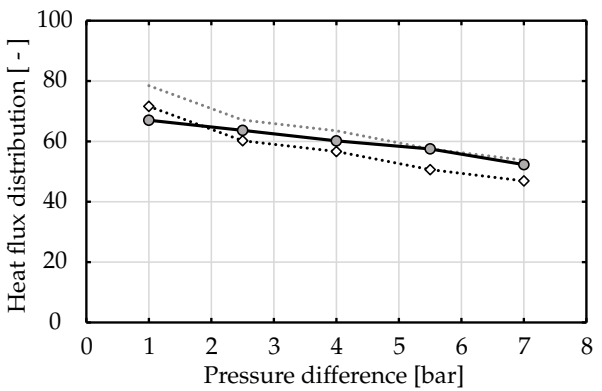

(f)

Figure 7. (a-e): Measuring points from experiment (0), Fit of the measured values from experiment (一), FE-Analysis $(\cdots)$, CFD with $\alpha_{\mathrm{b}}=$ adjusted (---), CFD with $\alpha_{\mathrm{b}}=100 \mathrm{~W} /\left(\mathrm{m}^{2} \mathrm{~K}\right)(\cdots)$, CFD with $\alpha_{\mathrm{b}}=1000 \mathrm{~W} /\left(\mathrm{m}^{2} \mathrm{~K}\right)(---) ;(\mathbf{f})$ : Heat flux distribution under variation of the pressure difference, Experiment $(\bullet \diamond \bullet)$, CFD $(-\infty)$, CFD (target) $(\cdots)$, (a) $\Delta \mathrm{p}=1.0$ bar, (b) $\Delta \mathrm{p}=2.5$ bar, (c) $\Delta \mathrm{p}=4.0$ bar, (d) $\Delta \mathrm{p}=5.5$ bar, (e) $\Delta \mathrm{p}=7.0$ bar.

The findings from the comparison of the rotor temperatures are also well reflected by the differences in the heat flux distributions (see Figure $7 \mathrm{f}$ ). The trend is quite well matched and the level of the heat flux distributions corresponds approximately to that of the experiment or FE analysis. Assuming that the slope of the experiment or FE analysis profile is correct, the heat flux distributions of the numerical simulation should follow the dotted line (...). For this purpose, the values from the experiment or the FE analysis $(\bullet \diamond \bullet)$ were transposed upwards until they corresponded to the value from the numerical simulation at the operating point with a differential pressure of $5.5 \mathrm{bar}$. This operating point was selected because the best agreement between numerical simulation and experiment was found there. If the dotted line (...) is used as a comparison level, it becomes clear that too little heat is introduced into the rotor at low pressure differences in the case of numerical simulation. In the case of the additional calculations with heat transfer coefficients of $\alpha_{\mathrm{b}}=100 \mathrm{~W} /\left(\mathrm{m}^{2} \mathrm{~K}\right)$ or $1000 \mathrm{~W} /\left(\mathrm{m}^{2} \mathrm{~K}\right)$, this level $(\cdots)$ is almost reached (not drawn in the diagram). However, other factors must also play a role, because, as shown above, the rotor temperatures are still calculated significantly too low. 


\section{Results of the Sensitivity Study}

So far, the comparison of the calculated and experimental results has shown that, at low pressure differences, the amount of heat into the rotor is underestimated by the numerical simulation. This seems to be a first indication that the heat transfer coefficients at the bristles were chosen too high. However, the fact that the temperature differences persist if the heat transfer coefficients are significantly reduced suggests that other effects or factors must also have a significant influence on the heat transfer. A possible explanation would be that the contact areas have been chosen too large and, thus, the specified specific total frictional power loss becomes too small (see Equation (21)). The package width or porosity are coupled with the leakage flow and they have been calibrated. However, a closer look at the bristle packages shows that in reality, not all of the bristles have exactly the same length. Therefore, it is possible that individual bristles do not come into contact with the rotor and consequently do not contribute to the conversion of the total frictional power loss. Photographs of the undersides of the bristle packages confirm this assumption (see Figure 8). This becomes particularly clear in the photograph shown in Figure 8a). In the area marked with the letter A, the bristles show clear signs of rubbing, whereas large parts (B) show no traces. Additionally, in the other pictures, a clear gradation of the bristles can be seen. It seems quite plausible that this effect especially occurs at low pressure differences.

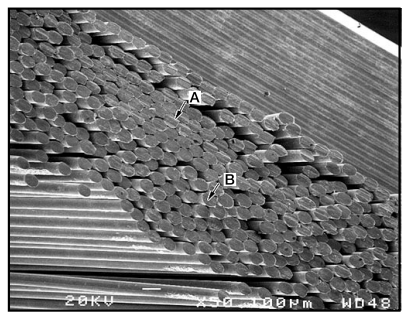

(a)

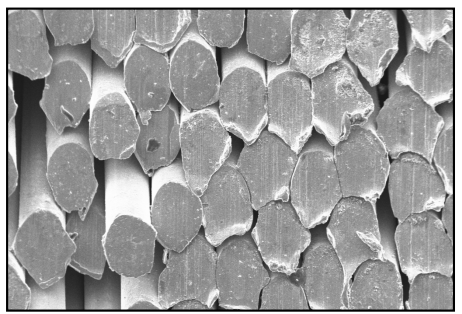

(b)

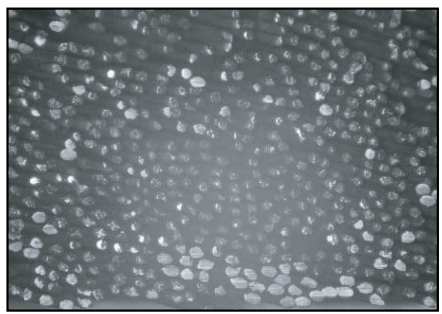

(c)

Figure 8. Zones with different contacts on the running surface; (a): Proctor et al. [42], (b): @ ITS, (c): Buscher [43].

A screening test was carried out for the test case at a medium pressure difference of 4.0 bar in order to investigate and quantify the influences. In addition to the influencing factors already identified, namely the heat transfer coefficients at the bristles $\alpha_{\mathrm{b}}$ and the contact surface $A$, the thermal conductivities of the materials of the bristles, the rotor and the seal housing were varied. The variation of the contact area was achieved by adjusting the specific total frictional power loss. Furthermore, it was examined whether the adjustment of the contact height of the bristles on the back plate $h_{\mathrm{BP}}$ has an influence. The latter factor was varied in three steps from $-10 \%$ over $0 \%$ to $+10 \%$, while the variation of the thermal conductivities covers the range of $\pm 5 \%$ supplemented by an additional step at $0 \%$. This corresponds approximately to the scattering of the available material data of the materials used. The heat transfer coefficients were varied in steps from $-50 \%$ over $0 \%$ to $+50 \%$. This is roughly in accordance with the fluctuations in the predictions of the correlations under consideration. The maximum reduction of the contact area was estimated with $-30 \%$ and the maximum increase in the contact area with $+5 \%$. For the central point, the contact area was $-12.5 \%$. The underlying test design complies with a definitive screening design, therefore comprising 13 tests.

The influences of the factors on the heat flux distribution and the maximum temperature in friction contact were investigated. The results of the investigation are summarized in a ma in effect diagram in Figure 9. Regarding the heat flux distribution, it can be concluded that the heat conductivities of the two direct friction partners $\left(\lambda_{\text {Bristle, }}, \lambda_{\text {Rotor }}\right)$ as well as the heat transfer coefficients at the bristles $\alpha_{\mathrm{b}}$ have a clear influence. The influences of the contact surface $A$ and the thermal conductivity of the seal housing $\lambda_{\text {Seal }}$ play a minor role. Adjusting the contact height of the bristles on the support ring $h_{\mathrm{BP}}$ does not result in a change in the heat flux distribution. This factor also has no influence on the maximum temperature in the friction 
contact. The contact temperature is mainly determined by the thermal conductivity of the rotor material $\lambda_{\text {Rotor }}$ and, to a greater extent, by the contact surface $A$.

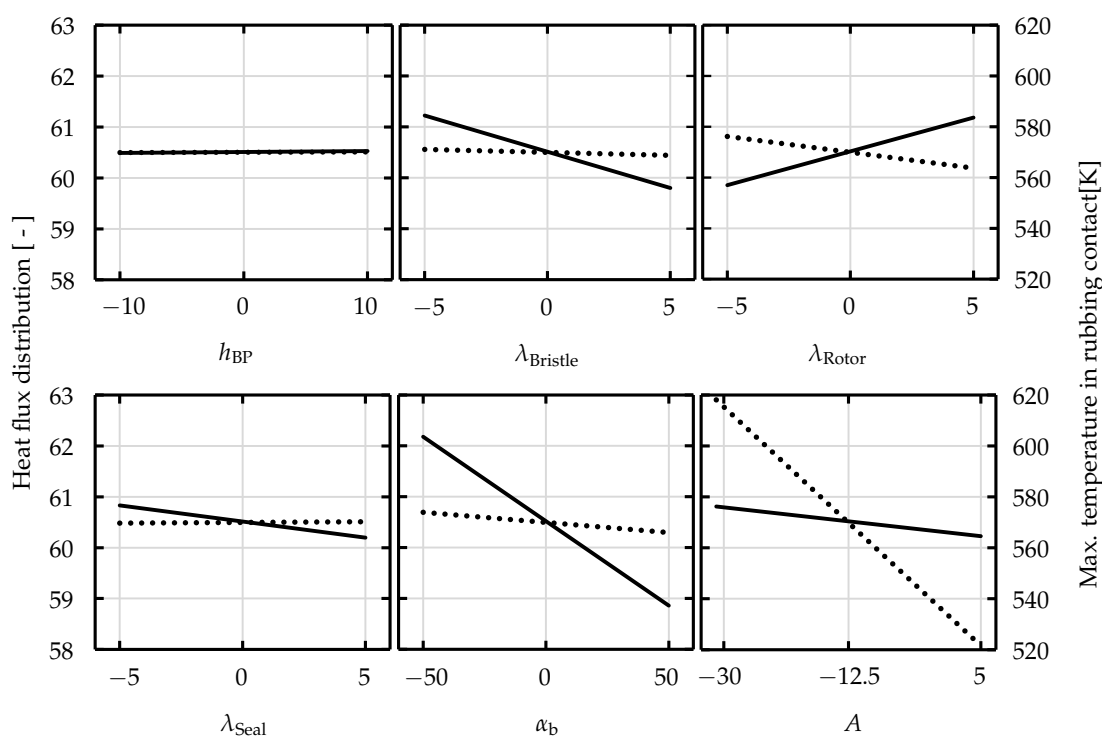

Figure 9. Main effect diagrams for heat flux distribution (-) and maximum temperature in rubbing contact $(\cdots \cdot)$.

A Pareto diagram of the standardized effects can be considered in order to be able to check which factors are significant (see Figure 10a,b). In this diagram, the absolute values of the standardized effects are shown in the order of their influence. The standardized effect is the observed effect divided by its standard deviation. The result corresponds to the $t$-value and is thus a measure of the significance of the effect. The selected significance level is $\alpha=0.05$. This results in a $t$-value of the reference line of 2.45 . If the bar of an effect extends beyond the reference line, it is significant. In the case of the heat flux distribution (see Figure 10a), this means that the heat transfer coefficients at the bristles are the decisive factor. The thermal conductivities of the rotor and bristle materials have a similarly strong effects and are also statistically significant. From the Pareto diagram for the maximum rubbing temperature in the friction contact as response variable (see Figure 10b), it is clear that the rubbing surface is the decisive factor by a large margin. The thermal conductivity of the rotor material is slightly significant.

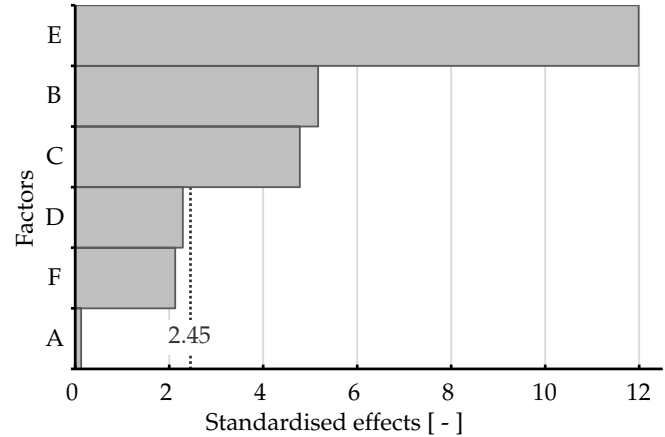

(a)

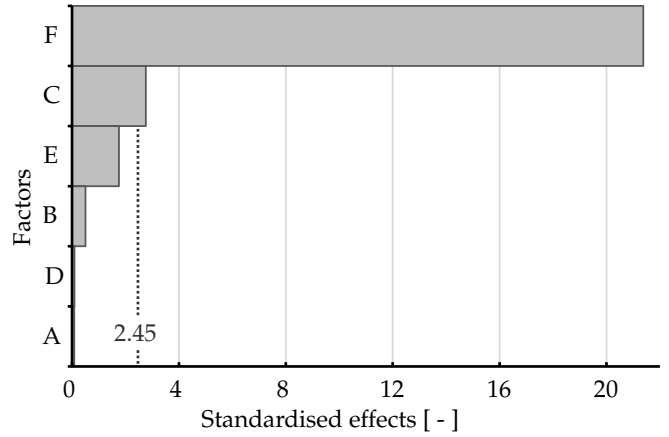

(b)

Figure 10. Pareto diagrams of standardized effects, significance level $\alpha=0,05, \mathrm{~A}: h_{\mathrm{BP}}, \mathrm{B}: \lambda_{\mathrm{Bristle}}$, C: $\lambda_{\text {Rotor }}, \mathrm{D}: \lambda_{\text {Seal }}, \mathrm{E}: \alpha_{\mathrm{b}}, \mathrm{F}: A$, (a): Response variable: Heat flux distribution, (b): Response variable: Max. temperature in rubbing contact.

The results of the screening test, in which the ma in influencing factors have been identified, are now to be transferred to all five test cases in order to obtain the influence 
of the pressure difference. The factors heat transfer coefficients at the bristles $\alpha_{\mathrm{b}}$, thermal conductivity of the rotor material $\lambda_{\text {Rotor }}$ and the contact surface $A$ are to be examined more closely. The thermal conductivity of the bristle material $\lambda_{\text {bristles }}$ was excluded, because the number of simulations to be performed had to be reduced. This limitation seems to be justified, since a similar effect on heat flux distribution is expected, as the thermal conductivity of the rotor material and the magnitudes of the effects are nearly the same.

The simulations were varied in accordance with a response surface design in the form of a central composite test plan. The design of a central composite design consists of a cube with two levels per factor. In addition, test points in the form of a star are also investigated. The star, starting from the central point, is created by varying the individual factors. Because the experimental points of the star exceed those of the cube, each factor is varied on five levels. With this type of experimental design, first- and second-order terms can be estimated. The range of the experimental design, in relation to the star points, corresponds to that of the screening test.

Figure 11 shows the effects of the three factors on the response variables heat flux distribution and maximum temperature in friction contact for all five test cases. As expected, the amount of heat that is introduced into the rotor increases as the thermal conductivity of the rotor material increases and decreases accordingly as the convective heat transfer at the bristles increases. The influence of the contact surface is only significant at low differential pressures. As a tendency, the changes of the varied parameters have less effect on the target value with increasing pressure difference. Thus, the effect of the pressure difference outweighs the three factors examined. This is not the case when evaluating the effects on the maximum temperature in the rubbing contact. Still apparent is the disproportionately strong influence of the contact surface on the temperature in the rubbing contact.
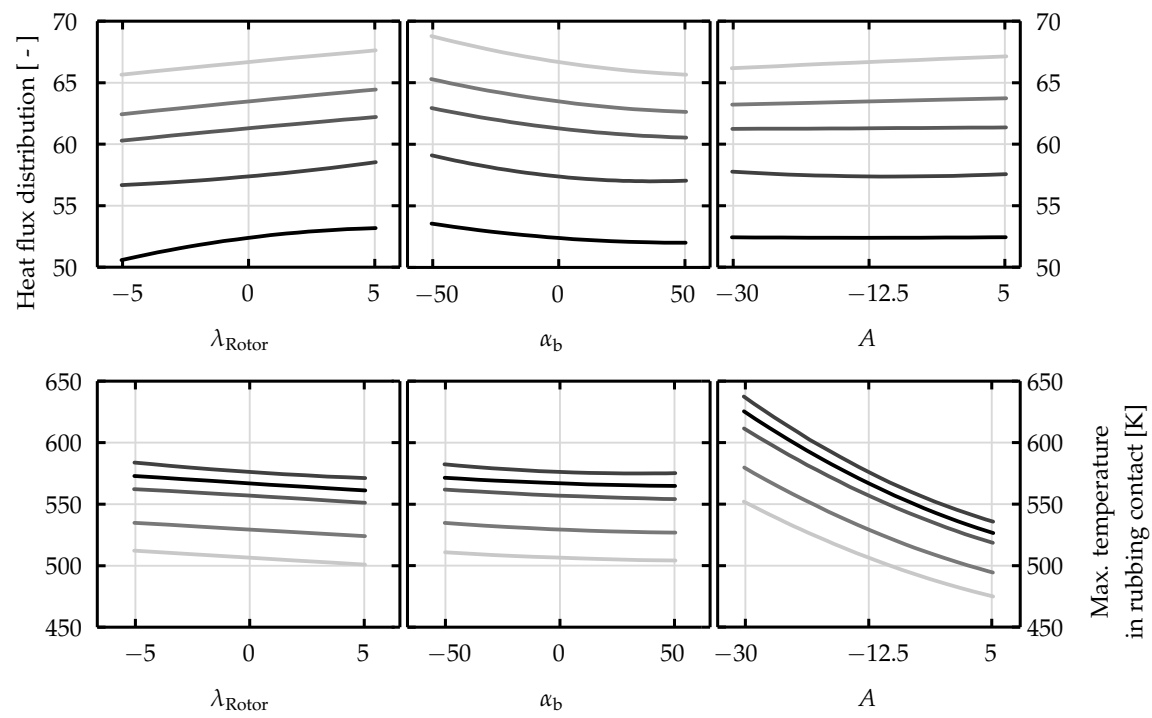

Figure 11. Main effect diagrams for heat flux distribution (top) and maximum temperature in rubbing contact (bottom); $\Delta \mathrm{p}=1.0$ bar $(-)-\Delta \mathrm{p}=7.0$ bar ( $(-)$.

In Figure 12a,b, the results of the simulation are plotted as standardized effects over the pressure difference. Instead of a Pareto chart, a line chart was chosen. The reference line at $t=2.23$ still represents the limit above which an effect is considered significant. Only those factors are shown in the diagrams whose effects are significant at least one pressure difference. In the case of heat flux distribution (see Figure 12a), it is clear, as outlined above, that the effects decrease significantly with increasing pressure difference. Except for the contact area $A(\boldsymbol{\sim}-)$, all applied factors rema in significant. The heat flux distribution is, however, increasingly determined by the increased pressure level and the convective heat transfer in the bristle package, which has increased in absolute numbers. Interaction effects between the individual factors are not significant. With regard to the maximum temperature in the contact area, the effects are not dependent on the pressure difference (see Figure 12b). 


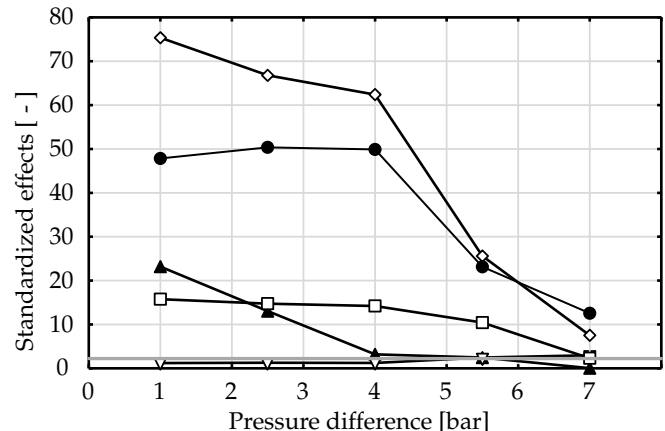

(a)

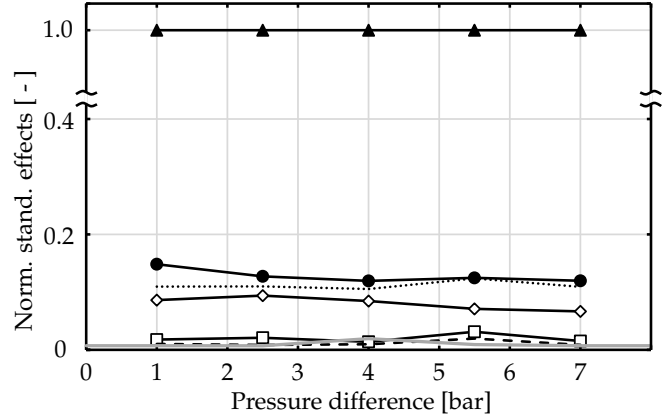

(b)

Figure 12. Standardized effects over variation of the pressure difference, significance level $\alpha=0.05$, $\lambda_{\text {Rotor }}(\boldsymbol{-}), \alpha_{\mathrm{b}}(\boldsymbol{\sim}), A(\boldsymbol{-}), \lambda_{\text {Rotor }} \times \lambda_{\text {Rotor }}(\boldsymbol{\nabla}), \alpha_{\mathrm{b}} \times \alpha_{\mathrm{b}}(\boldsymbol{-} \mathbf{-}), A \times A(\cdots \cdots), \lambda_{\text {Rotor }} \times A(\boldsymbol{-}-)$, Reference line $(-),(\mathbf{a})$ : Response variable: Heat flux distribution, (b): Response variable: Max. temperature in rubbing contact.

If the knowledge gained is transferred to the results that are discussed in Section 5, this means that a reduction of the heat transfer coefficients at the bristles, as well as a reduction of the contact area, should mainly affect the temperatures and heat flux distributions at low pressure differences. The corresponding values at high pressure differentials should show significantly smaller changes when varying the factors.

The parameter values listed in Table 2 were transferred to the five test cases and the numerical calculations were repeated in order to reduce the deviations in the temperature profiles between experiment and numerical simulation. In a first step, the thermal conductivity of the rotor was assumed to be constant. In any case, there is no change between the test cases, since the experiments always involved the same seal and the same rotor. However, if the thermal conductivity varies, the assumed values from Table 2 would probably have to be adjusted again, in order to achieve a match of the temperature profiles.

Table 2. Parameters of the numerical simulation.

\begin{tabular}{ccccc}
\hline Test Case & \multicolumn{2}{c}{ Heat Transfer Coefficient } & Rubbing Area & Thermal Conductivity \\
\hline $\boldsymbol{\Delta} \boldsymbol{p}$ & & $\boldsymbol{\alpha}_{\mathbf{b}}$ & $\boldsymbol{A}$ & $\boldsymbol{\lambda}_{\text {Rotor }}$ \\
\hline $1.0 \mathrm{bar}$ & $-96.5 \%$ & $\left(102 \mathrm{~W} /\left(\mathrm{m}^{2} \mathrm{~K}\right)\right)$ & $-17.5 \%$ & $\pm 0 \%$ \\
$2.5 \mathrm{bar}$ & $-85 \%$ & $\left(585 \mathrm{~W} /\left(\mathrm{m}^{2} \mathrm{~K}\right)\right)$ & $-10 \%$ & $\pm 0 \%$ \\
$4.0 \mathrm{bar}$ & $-77.5 \%$ & $\left(1148 \mathrm{~W} /\left(\mathrm{m}^{2} \mathrm{~K}\right)\right)$ & $-5 \%$ & $\pm 0 \%$ \\
5.5 bar & $-65 \%$ & $\left(2170 \mathrm{~W} /\left(\mathrm{m}^{2} \mathrm{~K}\right)\right)$ & $\pm 0 \%$ & $\pm 0 \%$ \\
$7.0 \mathrm{bar}$ & $-50 \%$ & $\left(3650 \mathrm{~W} /\left(\mathrm{m}^{2} \mathrm{~K}\right)\right)$ & $\pm 0 \%$ & $\pm 0 \%$ \\
\hline
\end{tabular}

In Figure 13a-e, the experimental rotor temperatures are plotted with the temperatures determined from the numerical simulations for all five test cases over the axial measuring position. The time points within the rubbing period of $30 \mathrm{~s}$ at which the highest temperatures occurred are shown. It is clear that the simulated temperatures at low pressure differences now correspond to the experimental values. At high pressure differences, the numerically calculated temperatures increase as compared to the original calculations, but they are still very close to the measured temperature values.

Additionally, the curve of the heat flux distribution over the pressure difference (see Figure 13f) now follows the slope resulting from the evaluation of the experimental data by means of the FE analysis. The values of the heat flux distribution that result from the results of the numerical simulation are now always higher than those of the FE analysis. There can be many reasons for this. Finally, it has to be considered that two numerical calculations are compared with each other, which can never exactly represent 
reality, despite careful verification and validation of the models. In Figure 13f, error bars are shown for a range of $\pm 10 \%$.

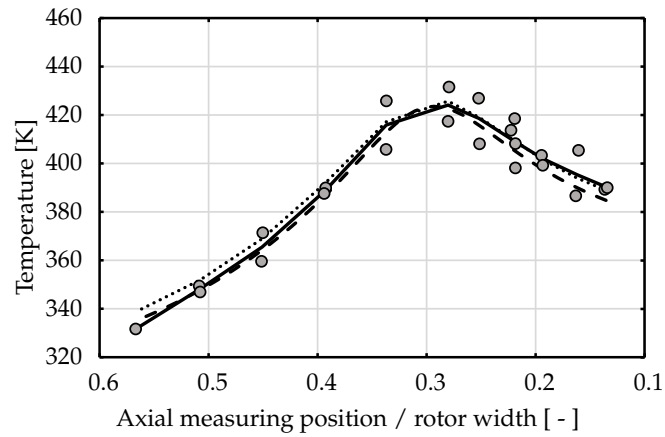

(a)

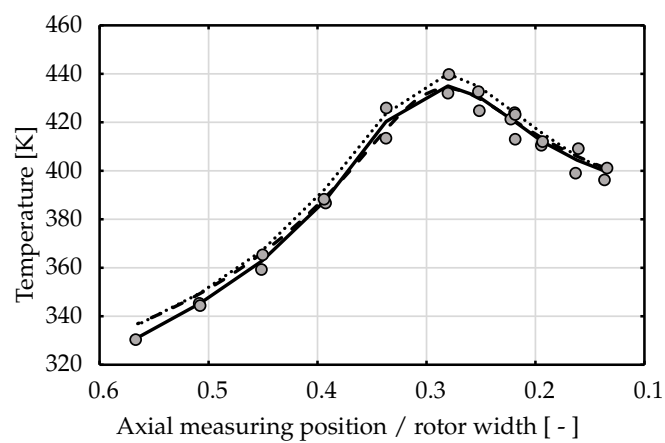

(c)

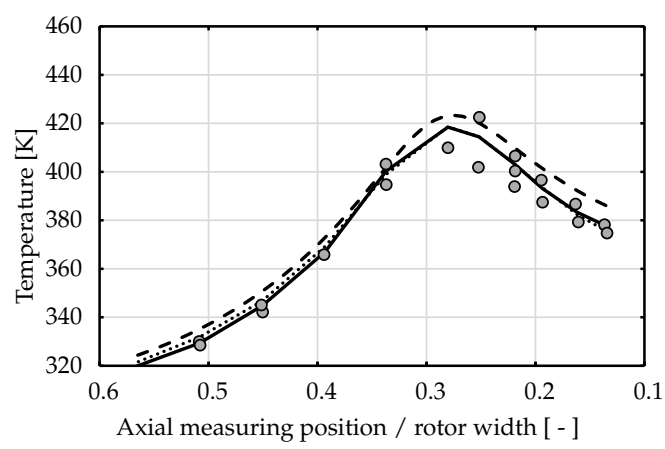

(e)

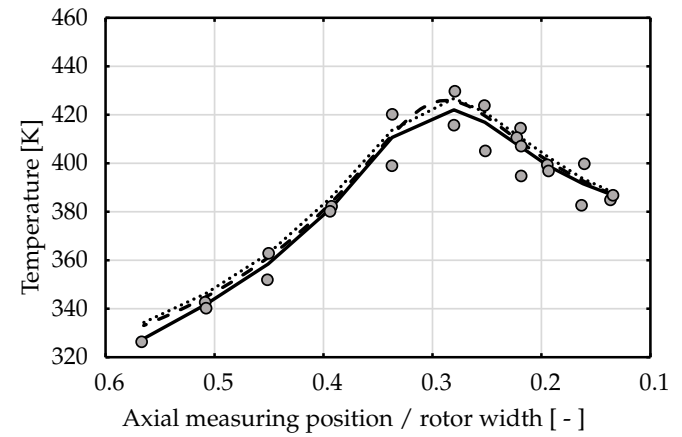

(b)

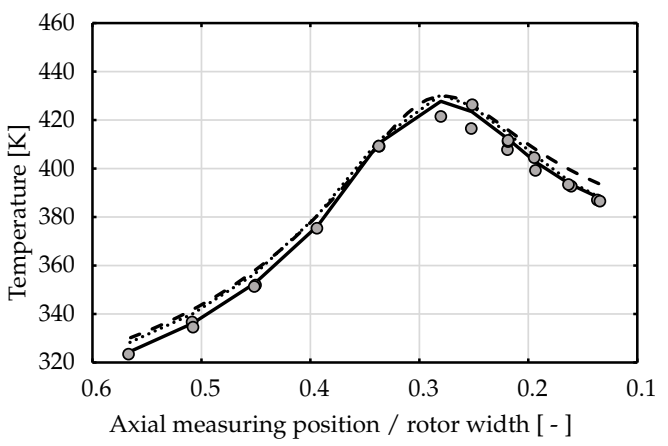

(d)

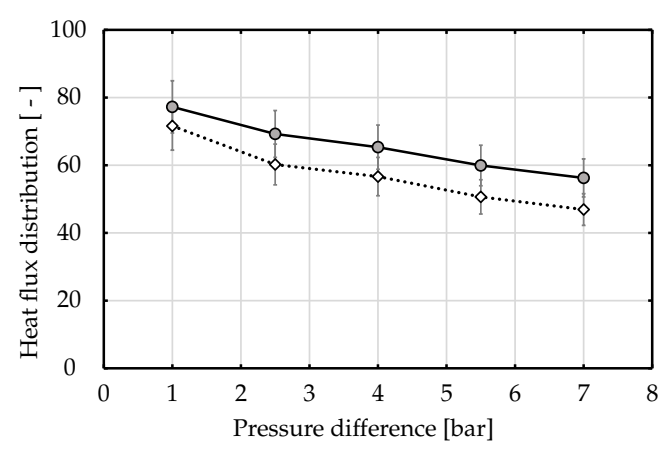

(f)

Figure 13. (a-e): Measuring points from experiment (o), Fit of the measured values from experiment (-), FE-Analysis (....), CFD (---); (f): Heat flux distribution under variation of the pressure difference, Experiment $(\bullet \diamond \bullet), \mathrm{CFD}(-\mathbf{-}),(\mathbf{a}) \Delta \mathrm{p}=1.0 \mathrm{bar},(\mathbf{b}) \Delta \mathrm{p}=2.5 \mathrm{bar},(\mathbf{c}) \Delta \mathrm{p}=4.0$ bar, (d) $\Delta \mathrm{p}=5.5 \mathrm{bar}$, (e) $\Delta \mathrm{p}=7.0$ bar.

\section{Conclusions}

The aim of the numerical analysis of the heat flux distribution was to identify the crucial factors for the heat transfer at the seal. The chosen approach was to model the bristle package as a porous medium. For the calculation of the porosity, in addition to the package width and radial height, an axial weighting was used for the first time to take that the bristle package is more strongly compressed under pressure in the vicinity of the back plate into account. Another new feature is the quantitative validation of such a model with experimental data from brush seal rub tests. Among other things, the calculations should serve to verify the applicability of the often used correlations for calculating the heat transfer coefficients at the bristles on the basis of banks of staggered tubes.

After the evaluation of the results, it has been shown that it is quite possible that the correlations for banks of staggered tubes used for brush seals significantly overestimate 
the heat transfer coefficients $\alpha_{\mathrm{b}}$. Besides the reasons already mentioned by Pfefferle [13] (see Section 1), the oblique flow of the bristles also has an influence here. When applying the correlations, a straight inflow is always assumed. Publications by Moreno and Sparrow [44] and Žukauskas [36] show that the Nusselt numbers decrease with increasing inclination. According to Žukauskas [36], the Nusselt numbers can decrease by approximately $20 \%$ with an oblique flow of $45^{\circ}$. If the oblique flow is increased to $80^{\circ}$, the values decrease to just above $40 \%$. As a result of the swirl that is caused by the rotor rotation and especially by the laying angle of the bristles, a straight inflow or flow through the bristle pack is not ensured to a large extent. Especially in the area close to the back plate, the flow follows very strongly the laying direction of the bristles (see Ref. [45]). Furthermore, the assumption of isotropic heat transfer coefficients throughout the package is a rough assumption. In addition, the correlations for calculating the heat transfer coefficients assume an average flow velocity in the package. In all literature sources applying these correlations to brush seals, this mean velocity is calculated by relating the total leakage mass flow to the gap area between the back plate and rotor. This results in average velocities that are too high. When compared to a bank of staggered tubes, the bristle package of a brush seal exhibits locally strong pressure and velocity differences. As a result, although very high convective heat transfer coefficients are conceivable on a localized basis, on average, the correlations overestimate the values.

Author Contributions: Conceptualization, M.H.; Methodology, M.H.; Formal analysis, M.H.; Investigation, M.H.; Resources, C.S. and H.-J.B.; Writing-original draft preparation, M.H.; Writing-review and editing, C.S. and H.-J.B.; Supervision, C.S. and H.-J.B.; Project administration, M.H., C.S. and H.J.B.; Funding acquisition, M.H., C.S. and H.-J.B. All authors have read and agreed to the published version of the manuscript.

Funding: This experimental work was funded by FVV ("Forschungsvereinigung Verbrennungskraftmaschinen e.V."), project number 1156. The APC was funded by the KIT-Publication Fund of the Karlsruhe Institute of Technology.

Institutional Review Board Statement: Not applicable

Informed Consent Statement: Not applicable

Data Availability Statement: Data sharing not applicable

Acknowledgments: The experimental investigations that served as a basis for this scientific publication are the result of a research project which has been initiated by the FVV ("Forschungsvereinigung Verbrennungskraftmaschinen e.V.") and carried out at the Institute of Thermal Turbomachinery, Karlsruhe Institute of Technology. The work has been supported financially by the FVV and the participating companies. This support is gratefully acknowledged.

Conflicts of Interest: The authors declare no conflict of interest.

\section{Abbreviations}

The following abbreviations are used in this manuscript:

a Normalized transverse bristle spacing, -

A Rubbing area, $\mathrm{m}^{2}$

A Viscosity tensor, $1 / \mathrm{m}^{2}$

$a_{\mathrm{i}} \quad$ Loss coefficient relating to viscosity, $1 / \mathrm{m}^{2}$

$a_{\mathrm{V}}, a_{\mathrm{fs}} \quad$ Specific surface, -

$A_{1} \quad$ Transversal bristle spacing, $\mathrm{m}$

$A_{2} \quad$ Diagonal bristle spacing, $\mathrm{m}$

$b \quad$ Normalized longitudinal bristle spacing, -

B Package width, $\mathrm{m}$ 


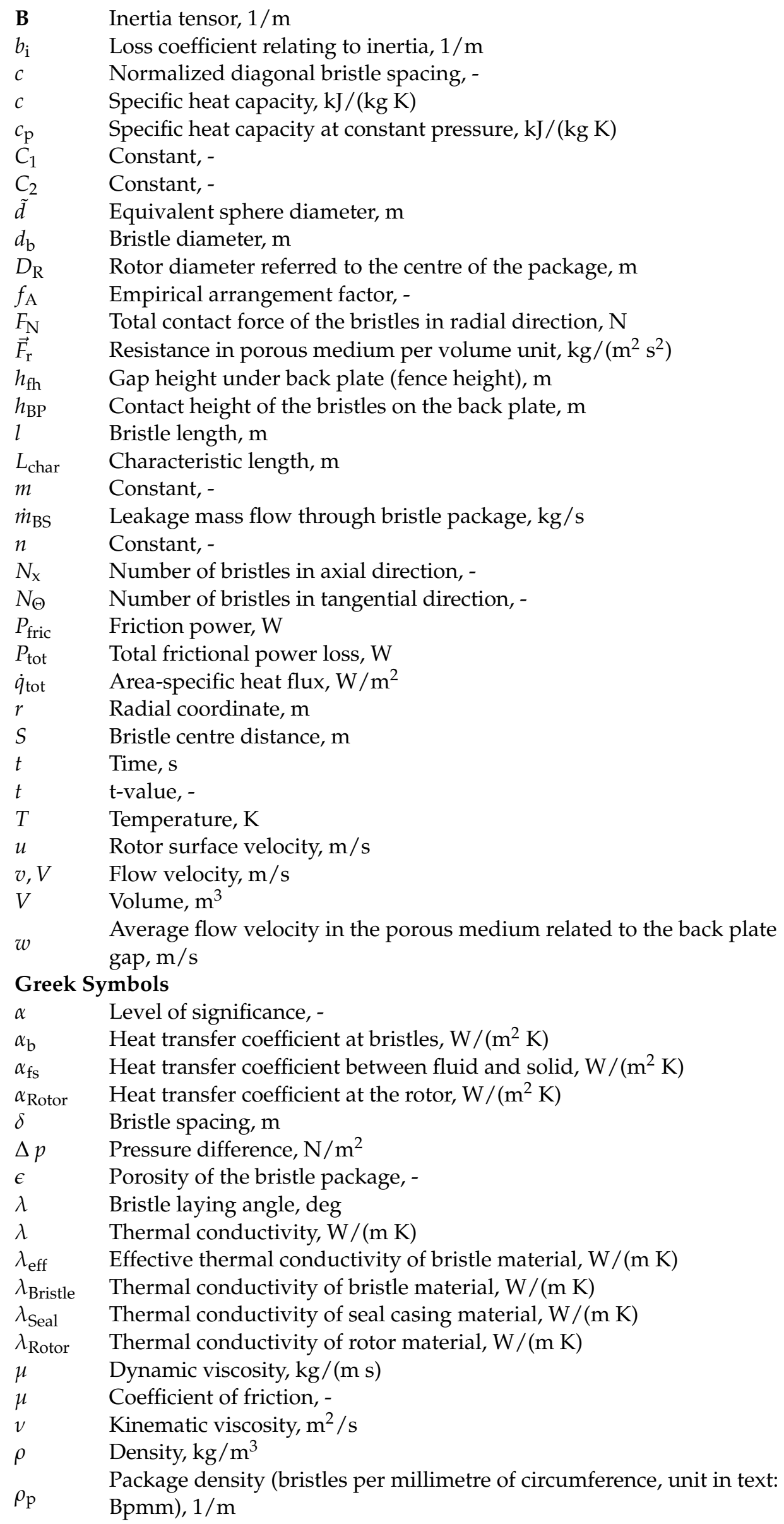




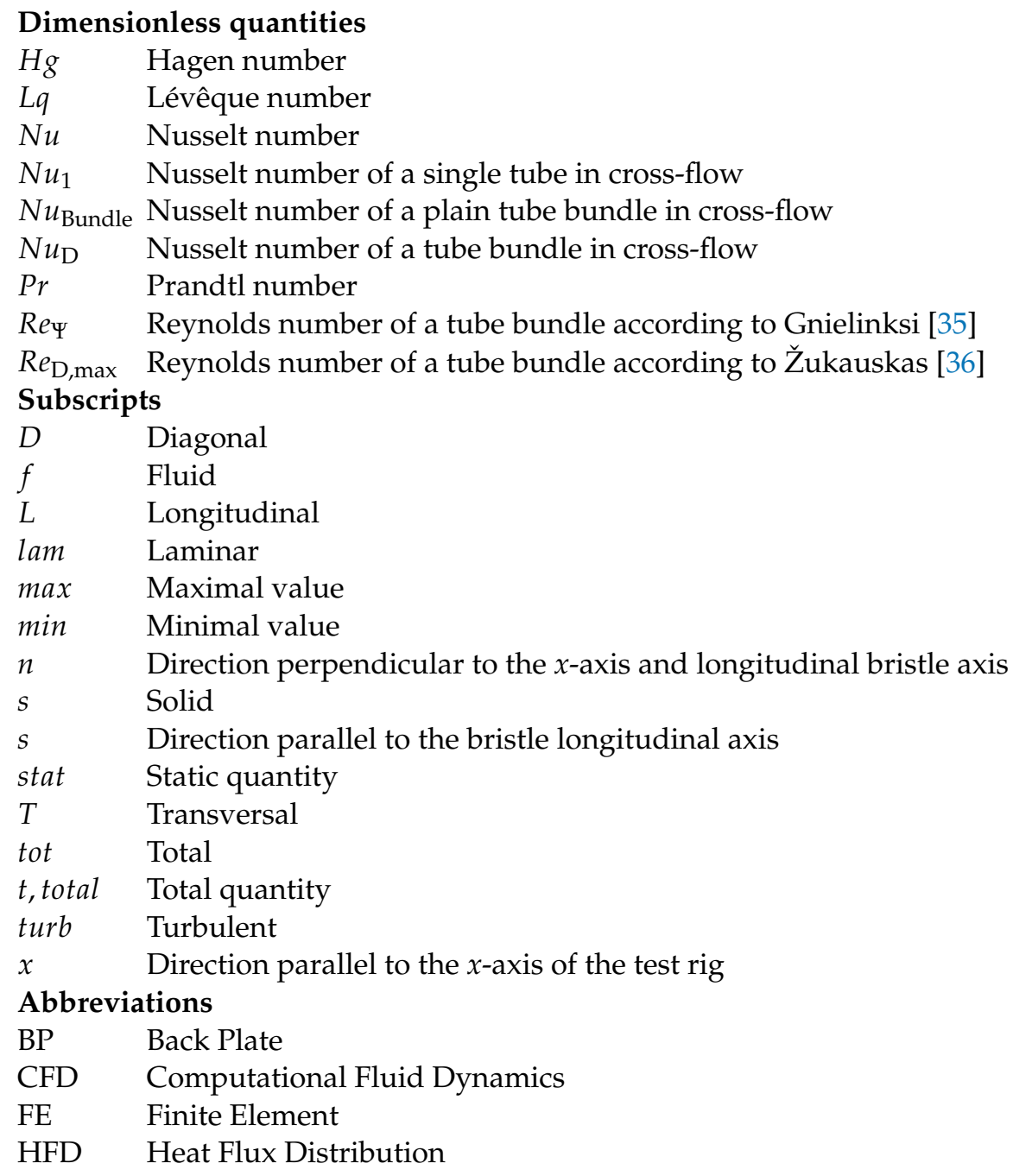

\section{Appendix A. Calculation of the Heat Transfer Coefficients at the Bristles}

The heat transfer coefficients $\alpha_{\mathrm{b}}$ are determined according to correlations for banks of staggered tubes by Gnielinski [35], Žukauskas [36], and Mart in [37]. Knowledge of the bristle spacing is required to apply the correlations. The characteristic quantities are shown in Figure A1. The assumptions are made that the bristles are staggered and the bristle spacing is identical at the same radial height in all directions $\left(A_{1}=A_{2}=\delta\right)$.

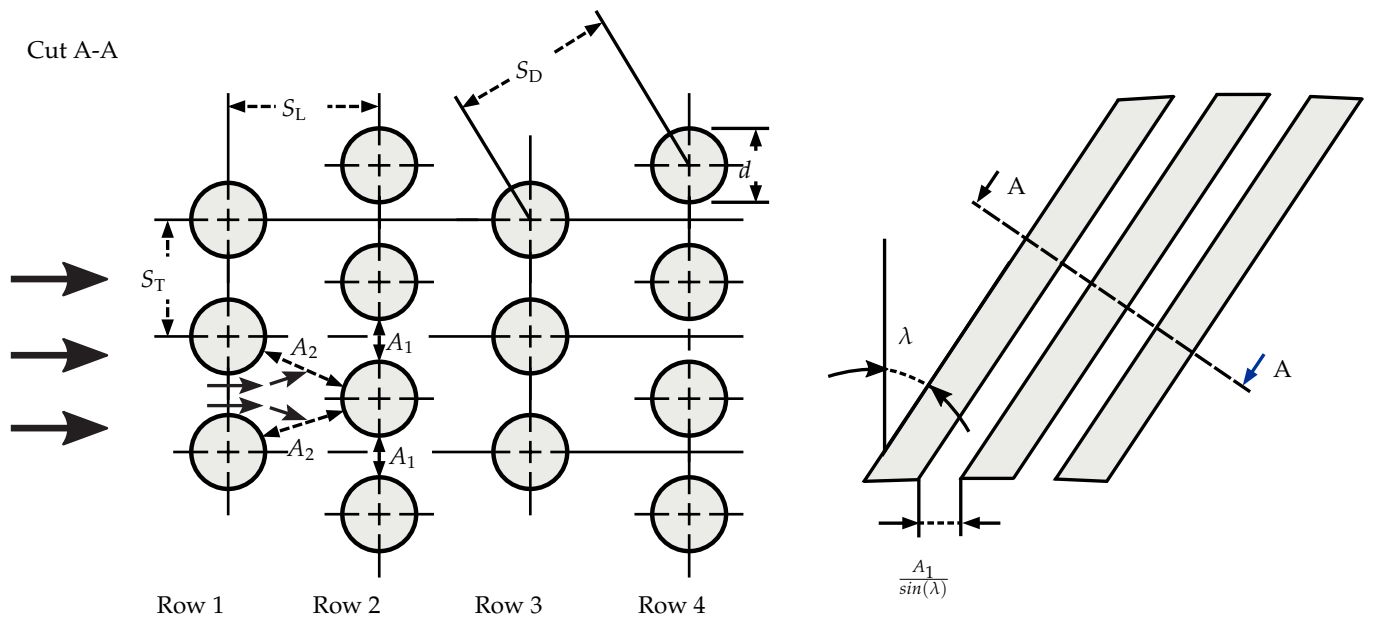

Figure A1. Arrangement of bristles in bristle package. 
To calculate the bristle spacing $\delta$, four equations with four unknowns are available. The bristle width $B$ is known in relation to the radial bristle height.

1. Number of rows in flow direction $N_{\mathrm{x}}$ :

$$
N_{\mathrm{x}}=\frac{B-d_{\mathrm{b}}}{S_{\mathrm{L}}}+1
$$

2. Bristle spacing in flow direction $S_{\mathrm{L}}$ :

$$
S_{\mathrm{L}}=\sqrt{\left(d_{\mathrm{b}}+\delta\right)^{2}-1 / 4\left(d_{\mathrm{b}}+\delta\right)^{2}}=\frac{\sqrt{3}}{2}\left(d_{\mathrm{b}}+\delta\right)
$$

3. Bristle spacing $\delta$ :

$$
\delta=\left(\frac{\pi D_{\mathrm{R}}}{N_{\Theta}}-\frac{d_{\mathrm{b}}}{\sin (\lambda)}\right) \sin (\lambda)
$$

4. Number of bristles in circumferential direction $N_{\Theta}$ :

$$
N_{\Theta}=\frac{N}{N_{\mathrm{x}}}
$$

Appendix A.1. Calculation of Heat Transfer Coefficients According to Gnielinski

The average Nusselt number of a cross-flow plain tube bundle is calculated according to Gnielinski [35] from the average Nusselt number of a cross-flow single tube multiplied by an arrangement factor $f_{\mathrm{A}}$ :

$$
N u_{\text {Bundle }}=f_{\mathrm{A}} N u_{1} .
$$

For a single tube, Equation (A6) applies:

$$
N u_{1}=0.3+\sqrt{N u_{1, \text { lam }}^{2}+N u_{1, \text { turb }}^{2}}
$$

with

$$
N u_{1, \text { lam }}=0.664 \sqrt{R e_{\Psi, 1}} \sqrt[3]{\operatorname{Pr}}
$$

and

$$
N u_{1, \text { turb }}=\frac{0.037 \operatorname{Re}_{\Psi, 1}^{0.8} \operatorname{Pr}}{1+2.443 \operatorname{Re}_{\Psi, 1}^{-0.1}(\operatorname{Pr}(2 / 3)-1)} .
$$

The Reynolds number is calculated according to:

$$
\operatorname{Re}_{\Psi, 1}=\frac{w L_{\mathrm{char}}}{\Psi v}, \quad 10<\operatorname{Re}_{\Psi, 1}<10^{6} .
$$

The characteristic length is $L_{\mathrm{char}}=\frac{\pi}{2} d_{\mathrm{b}}$. As void fraction $\Psi$ the average porosity of the bristle pack is used. The velocity $w$ related to the fence height is calculated as follows:

$$
w=\frac{\dot{m}_{\mathrm{BS}}}{\rho \pi\left(\left(\frac{D_{\mathrm{R}}}{2}+h_{\mathrm{fh}}\right)^{2}-\frac{D_{\mathrm{R}}^{2}}{2}\right)} .
$$

In $\operatorname{Pr} a$ is the thermal conductivity of the flow medium.

$$
\operatorname{Pr}=\frac{v}{a}, \quad 0.6<\operatorname{Pr}<10^{3}
$$

In the case of staggered arrangement, the arrangement factor $f_{\mathrm{A}}$ is:

$$
f_{\mathrm{A}}=1+\frac{2 d_{\mathrm{b}}}{3 S_{\mathrm{L}}} .
$$


The material properties of the flow medium are related to the average temperature of the inlet and outlet of the bristle package.

\section{Appendix A.2. Calculation of Heat Transfer Coefficients According to Žukauskas}

The average Nusselt number for heat transfer in a cross-flow tube bundle is calculated according to Žukauskas [36] as:

$$
N u_{\mathrm{D}}=C_{1} C_{2} R e_{\mathrm{D}, \max }^{m} \operatorname{Pr}^{0.36}\left(\frac{P r}{P r_{\mathrm{s}}}\right)^{1 / 4}
$$

The correlation is valid for: $0.7 \lesssim \operatorname{Pr} \lesssim 500$ and $10 \lesssim R e_{\mathrm{D}, \max } \lesssim 2 \times 10^{6}$ and a number of tubes in axial direction of $N_{\mathrm{x}} \geq 20$. All material properties of the flow medium, with the exception of $P r_{\mathrm{s}}$, are related to the average temperature of the inlet and outlet of the bristle package.

For a staggered arrangement with $S_{\mathrm{T}} / S_{\mathrm{L}}<2$ and $10^{3}<R e_{\mathrm{D}, \max }<2 \times 10^{5}$

$$
C_{1}=0.35\left(\frac{S_{\mathrm{T}}}{S_{\mathrm{L}}}\right)^{1 / 5} \text { and } m=0.60
$$

applies.

$C_{2}=0.99$ since $N_{\mathrm{x}}<20$. The Reynolds number is calculated as:

$$
R e_{\mathrm{D}, \max }=\frac{w_{\max } d_{\mathrm{b}}}{v}
$$

with

$$
w_{\max }=\frac{S_{\mathrm{T}}}{S_{\mathrm{T}}-d_{\mathrm{b}}} w
$$

For w, Equation (A10) applies.

Appendix A.3. Calculation of Heat Transfer Coefficients According to Martin

An alternative to the approaches by Gnielinski [35] and Žukauskas [36] is the calculation approach by Mart in [37]. The method used is based on the so-called Lévêque analogy. This links the pressure loss and the heat transfer coefficients.

The following applies to staggered tube bundles:

$$
N u=0.404 L q^{1 / 3}
$$

with the Lévêque number for $b=S_{\mathrm{L}} / d_{\mathrm{b}}<1$ :

$$
L q=0.92 H g \operatorname{Pr}(4 a b / \pi-1)(b c), \quad \text { with } a=\frac{S_{\mathrm{T}}}{d_{\mathrm{b}}}=\frac{S_{\mathrm{D}}}{d_{\mathrm{b}}}=c .
$$

The Hagen number is:

$$
H g=H g_{\text {lam }}+H g_{\text {turb }}\left(1-\exp \left(1-\left(R e_{\mathrm{D}, \max }+200\right) / 1000\right)\right),
$$

with

$$
\begin{array}{r}
H g_{\text {lam }}=140 R e_{\mathrm{D}, \max }\left(\left(b^{0.5}-0.6\right)^{2}+0.75\right) \\
/\left(a^{1.6}(4 a b / \pi-1)\right)
\end{array}
$$

and

$$
H g_{\text {turb }}=f_{\mathrm{t}, \mathrm{s}} R e_{\mathrm{D}, \text { max }}^{1.75}+f_{\mathrm{t}, \mathrm{n}} R e_{\mathrm{D}, \text { max }^{\prime}}^{2}
$$

where $f_{\mathrm{t}, \mathrm{n}}$ for $N_{\mathrm{x}}>10$ becomes zero 
For $f_{\mathrm{t}, \mathrm{s}}$

$$
\begin{array}{r}
f_{\mathrm{t}, \mathrm{s}}=1.25+0.6 /(a-0.85)^{1.08}+0.2(b / a-1)^{3} \\
-0.005(a / b-1)^{3} .
\end{array}
$$

applies.

For $R e_{\mathrm{D}, \max }$, Equation (A15) is valid.

\section{References}

1. Dinc, O.S.; Reluzco, G.; Turnquist, N.A.; Lawen, J.; Kerber, O.; Brunner, F.; Crum, G.; Stuck, A.; Cromer, R.; Marks, P. Brush Seals in Industrial Gas Turbines-Turbine Section Interstage Sealing. In Proceedings of the 34th AIAA/ASME/SAE/ASEE Joint Propulsion Conference and Exhibit, Cleveland, OH, USA, 13-15 July 1998; Volume AIAA98-3175. [CrossRef]

2. Aksit, M.F.; Tichy, J.A. Wear of Brush Seals: Background and New Modeling Approach. Tribol. Trans. 1998, 41, 368-374. [CrossRef]

3. Gorelov, G.M.; Reznik, V.E.; Tsibizov, V.I. Experimental Study of Brush Seal Flow Characteristics and Comparison with a Labyrinth Seal. Izv. Vuz. Aviatsionnaia Tekhnika 1988, 31, 43-46.

4. Stephen, D.; Hogg, S.I. Development of Brush Seal Technology for Steam Turbine Retrofit Applications. In Proceedings of the 2003 International Joint Power Generation Conference Power, Atlanta, GA, USA, 16-19 June 2003; pp. 505-512. [CrossRef]

5. Doğu, Y.; Aksit, M.F. Brush Seal Temperature Distribution Analysis.J. Eng. Gas Turbines Power 2006, 128, 599. [CrossRef]

6. Demiroglu, M.; Gursoy, M.; Tichy, J.A. An Investigation of Tip Force Characteristics of Brush Seals. In Proceedings of the ASME Turbo Expo 2007, Montreal, QC, Canada, 14-17 May 2007; Voume 4: Parts A and B, pp. 1249-1260. [CrossRef]

7. Demiroglu, M.; Tichy, J.A. An Investigation of Heat Generation Characteristics of Brush Seals. In Proceedings of the ASME Turbo Expo 2007, Montreal, QC, Canada, 14-17 May 2007; Volume 4 Parts A and B, pp. 1261-1270. [CrossRef]

8. Ruggiero, E.J.; Allen, J.; Demiroglu, M.; Lusted, R.M. Heat Generation Characteristics of a Kevlar Fiber Brush Seal. In Proceedings of the 43rd AIAA/ASME/SAE/ ASEE Joint Propulsion Conference \& Exhibit, Cincinnati, OH, USA, 8-11 July 2007; Volum AIAA2007-5738, [CrossRef]

9. Ruggiero, E.J.; Allen, J.; Lusted, R.M. Heat Generation Characteristics of a Carbon Fiber Brush Seal. In Proceedings of the 44th AIAA/ASME/SAE/ASEE Joint Propulsion Conference \& Exhibit, Hartford, CT, USA, 21-23 July 2008; Volume AIAA2008-4508. [CrossRef]

10. Qiu, B.; Li, J. Numerical Investigations on the Heat Transfer Behavior of Brush Seals Using Combined Computational Fluid Dynamics and Finite Element Method. J. Heat Transf. 2013, 135, 122601. [CrossRef]

11. Qiu, B.; Li, J.; Feng, Z. Investigation of Conjugate Heat Transfer in Brush Seals Using Porous Media Approach Under Local Thermal Non-Equilibrium Conditions. In Proceedings of the ASME Turbo Expo: Turbine Technical Conference and Exposition-2014, Montreal, QC, Canada, 15-19 June 2015; Volume 5C: Heat Transfer, p. V05CT15A009, [CrossRef]

12. Pfefferle, D.; Dullenkopf, K.; Bauer, H.J. Design and Validation of a New Test Rig for Brush Seal Testing Under Engine Relevant Conditions. In Proceedings of the ASME Turbo Expo 2011, Vancouver, BC, Canada, 6-10 June 2011; Volume 5: Heat Transfer, Parts A and B, pp. 679-689. [CrossRef]

13. Pfefferle, D. Untersuchung des Wärmeeintrags und der Reibleistung Anstreifender Bürstendichtungen: Dissertation; Forschungsberichte aus dem Institut für Thermsiche Strömungsmaschinen, Logos Verlag: Berlin, Germany, 2017; Volume 65.

14. Braun, M.J.; Hendricks, R.C.; Canacci, V. Flow Visualization in a Simulated Brush Seal. In Proceedings of the ASME 1990 International Gas Turbine and Aeroengine Congress and Exposition, Brussels, Belgium, 11-14 June 1990; p. V005T16A008. [CrossRef]

15. Owen, A.K.; Jones, T.V.; Guo, S.M.; Hogg, S.I. An Experimental and Theoretical Study of Brush Seal and Shaft Thermal Interaction. In Proceedings of the ASME Turbo Expo 2003, Atlanta, GA, USA, 16-19 June 2003; Volume 5: Turbo Expo 2003, Parts A and B, pp. 977-984. [CrossRef]

16. Doğu, Y. Investigation of Brush Seal Flow Characteristics Using Bulk Porous Medium Approach. In Proceedings of the ASME Turbo Expo 2003, Atlanta, GA, USA, 16-19 June 2003; Volume 5: Turbo Expo 2003, Parts A and B, pp. 1091-1101. [CrossRef]

17. Hildebrandt, M.R.; Schwarz, H.; Schwitzke, C.; Bauer, H.J.; Friedrichs, J. Effects of the Back Plate Inner Diameter on the Frictional Heat Input and General Performance of Brush Seals. Aerospace 2018, 5, 58. [CrossRef]

18. Hildebrandt, M.; Schwitzke, C.; Bauer, H.J. Experimental Investigation on the Influence of Geometrical Parameters on the Frictional Heat Input and Leakage Performance of Brush Seals. J. Eng. Gas Turbines Power 2019, 141, 042504. [CrossRef]

19. Hildebrandt, M.; Schwitzke, C.; Bauer, H.J. Contamination of Brush Seals by Oil and Salt and Its Impact on Rubbing and Hysteresis Behaviour. Int. J. Turbomach. Propuls. Power 2019, 4, 40. [CrossRef]

20. Hildebrandt, M.; Munz, O.; Schwitzke, C.; Bauer, H.J. Experimental Study on the Waer- in Behaviour of Brush Seals. In Proceedings of the ASME Turbo Expo: Turbine Technical Conference and Exposition—2020, Online, 21-25 September 2020; p. 999.

21. Hildebrandt, M. E in Beitrag zum Verständnis des Anstreif- und Leckageverhaltens von Bürstendichtungen bei Variation geometrischer Parameter, Dissertation; Forschungsberichte aus dem Institut für Thermsiche Strömungsmaschinen, Logos Verlag: Berlin, Germany, 2021 ; Volume 82.

22. Darcy, H. Les Fontaines Publiques de la Ville de Dijon: Exposition et Application des Principes a Suivre et des Formules a Employer dans les Questions de Distribution D'Eau; Victor Dalmont: Paris, France, 1856.

23. Forchheimer, P.H. Wasserbewegung durch Boden. Z. Acker Pflanzenbau 1901, 49, 1736-1749. 
24. Ergun, S. Fluid Flow Through Packed Columns. Chem. Eng. Prog. 1952, 48, 89-94.

25. Chew, J.W.; Hogg, S.I. Porosity Modeling of Brush Seals. J. Tribol. 1997, 119, 769. [CrossRef]

26. Pröstler, S. Modellierung und Numerische Berechnung von Wellenabdichtungen in Bürstenbauart: Zugl. Dissertation an der RuhrUniversität Bochum 2005; Dr. Hut: München, Germany, 2005.

27. Chew, J.W.; Lapworth, B.L.; Millener, P.J. Mathematical Modeling of Brush Seals. Int. J. Heat Fluid Flow 1995, 16, 493-500. [CrossRef]

28. Nield, D.A.; Bejan, A. Convection in Porous Media, 5th ed.; Springer: Cham, Switzerland, 2017.

29. Kaviany, M. Principles of Heat Transfer in Porous Media, 2nd ed.; Mechanical Engineering Series; Springer: New York, NY, USA, 1995.

30. Chen, L.H.; Wood, P.E.; Jones, T.V.; Chew, J.W. Detailed Experimental Studies of Flow in Large Scale Brush Seal Model and a Comparison With CFD Predictions. J. Eng. Gas Turbines Power 2000, 122, 672. [CrossRef]

31. Schur, F.; Friedrichs, J.; Flegler, J.; Georgakis, C.; Polklas, T. Pressure Distributions Below Brush Seals at Varying Operating Conditions. In Proceedings of the ASME Turbo Expo: Turbine Technical Conference and Exposition-2018, Oslo, Norway, 11-15 June 2018; Volume GT2018-76194. [CrossRef]

32. Guardino, C.; Chew, J.W. Numerical Simulation of 3D Bristle Bending in Brush Seals. In Proceedings of the ASME Turbo Expo 2004, Vienna, Austria, 14-17 June 2004; Volume 4: Turbo Expo 2004, pp. 277-288. [CrossRef]

33. Aksit, M.F. Analysis of Brush Seal Bristle Stresses With Pressure-Friction Coupling. In Proceedings of the ASME Turbo Expo 2003, Atlanta, GA, USA, 16-19 June 2003; Volume 5: Turbo Expo 2003, Parts A and B, pp. 1061-1069. [CrossRef]

34. Aksit, M.F.; Doğu, Y.; Kandemir, I.; Kizil, H. An Investigation of Pressure Stiffness Coupling in Brush Seals. In Proceedings of the Eleventh International Symposium on Transport Phenomena and Dynamics of Rotating Machinery 2006, Honolulu, HI, USA, 26 February-2 March 2006; Volume ISROMAC-11-4.

35. Gnielinski, V. Querumströmte Einzelne Rohreihen und Rohrbündel. In VDI-Wärmeatlas; Springer Reference, Springer Vieweg: Berlin, Germany, 2013; pp. 819-823.

36. Žukauskas, A. Heat Transfer from Tubes in Crossflow. In Advances in Heat Transfer; Advances in Heat Transfer; Hartnett, J.P., Irvine, T., Eds.; Academic Press: New York, NY, USA, 1972; Volume 8, pp. 93-160. [CrossRef]

37. Martin, H. The Generalized Lévêque Equation and its Practical use for the Prediction of Heat and Mass Transfer Rates from Pressure Drop. Chem. Eng. Sci. 2002, 57, 3217-3223. [CrossRef]

38. Pekris, M.J.; Franceschini, G.; Gillespie, D. Effect of Geometric Changes in an Idealised Contacting Brush Seal Bristle Pack on Typical Key Performance Measures. In Proceedings of the ASME Turbo Expo 2011, Vancouver, BC, Canada, 6-10 June 2011; Volume 5: Heat Transfer, Parts A and B, pp. 999-1010. [CrossRef]

39. Kudriavtsev, V.V.; Braun, M.J. Model Developments for the Brush Seal Numerical Simulation. J. Propuls. Power 1996, $12,193-201$. [CrossRef]

40. Hendricks, R.C.; Kudriavtsev, V.V.; Braun, M.J.; Athavale, M.M. Flows in Pinned Arrays Simulating Brush Seals. In Proceedings of the Sixth International Congress on Fluid Dynamics and Propulsion, Cairo, Egypt, 29-31 December 1996; pp. 258-266.

41. Bayley, F.J.; Long, C.A. A Combined Experimental and Theoretical Study of Flow and Pressure Distributions in a Brush Seal. J. Eng. Gas Turbines Power 1993, 115, 404. [CrossRef]

42. Proctor, M.P.; Walker, J.F.; Perkins, H.D.; Hoopes, J.F.; Williamson, G.S. Brush Seals for Cryogenic Applications: Performance, Stage Effects, and Preliminary Wear Results in LN2 and LH2: NASA Technical Paper 3536; NASA: Washington, DC, USA, 1996.

43. Büscher, S. Untersuchung von Mehrstufigen Bürstendichtugnen für Dampfturbinen: Dissertation; Mitteilungen des Pfleiderer-Instituts für Strömungsmaschinen; Verlag und Bildarchiv W.H. Faragallah: Sulzbach, Germany, 2010; Volume 15.

44. Moreno, A.; Sparrow, E.M. Heat Transfer, Pressure Drop, and Fluid Flow Patterns in Yawed Tube Banks. Int. J. Heat Mass Transf. 1987, 30, 1979-1995. [CrossRef]

45. Franceschini, G.; Jones, T.V.; Gillespie, D. Improved Understanding of Blow-Down in Filament Seals. J. Turbomach. 2010, 132, 41004. [CrossRef] 